\title{
Normal Glucose-Induced Suppression of Glucose Production But Impaired Stimulation of Glucose Disposal in Type 2 Diabetes Evidence for a Concentration-Dependent Defect in Uptake
}

\author{
Michael F. Nielsen, Rita Basu, Steven Wise, Andrea Caumo, Claudio Cobelli, and Robert A. Rizza
}

\begin{abstract}
The present studies were undertaken to determine whether people with type 2 diabetes are resistant to the effects of glucose as well as insulin. Diabetic and nondiabetic subjects were studied on three occasions. Hormone secretion was inhibited with somatostatin. Insulin concentrations were kept at "basal" levels (referred to as low insulin infusion) from 0 to $180 \mathrm{~min}$ then increased to $200 \mathrm{pmol} / \mathrm{l}$ from 181 to $360 \mathrm{~min}$ (referred to as high insulin infusion). Glucose concentrations were clamped at either $\sim 95, \sim 130$, or $\sim 165$ $\mathrm{mg} / \mathrm{dl}$ on each occasion. In the presence of basal insulin concentrations, a progressive increase in glucose from 95 to 130 to $165 \mathrm{mg} / \mathrm{dl}$ was accompanied by a comparable and progressive decrease ( $P=0.001$ to 0.003 by analysis of variance [ANOVA]) in endogenous glucose production (measured with $\left[6-{ }^{3} \mathrm{H}\right]$ glucose) and total glucose output (measured with $\left[2 \cdot{ }^{3} \mathrm{H}\right]$ glucose) and incorporation of ${ }^{14} \mathrm{CO}$ into glucose (an index of gluconeogenesis) in both diabetic and nondiabetic subjects, indicating normal hepatic (and perhaps renal) response to glucose. In the nondiabetic subjects, an increase in glucose concentration from 95 to 130 to $165 \mathrm{mg} / \mathrm{dl}$ resulted in a progressive increase in glucose disappearance during both the low $(19.9 \pm 1.8$ to $23.6 \pm 1.8$ to $25.4 \pm 1.6$ $\mu \mathrm{mol} \cdot \mathrm{kg}^{-1} \cdot \mathrm{min}^{-1} ; \mathrm{P}=\mathbf{0 . 0 0 3}$ by ANOVA) and high (36.4 \pm 3.1 to $47.6 \pm 4.5$ to $61.1 \pm 7.0 \mu \mathrm{mol} \cdot \mathrm{kg}^{-1} \cdot \mathrm{min}^{-1} ; \mathrm{P}=$ 0.001 by ANOVA) insulin infusions. In contrast, in the diabetic subjects, whereas an increase in glucose from 95 to $130 \mathrm{mg} / \mathrm{dl}$ resulted in an increase in glucose disappearance during both the low $(P=0.001)$ and high ( $P$ $=0.01$ ) dose insulin infusions, a further increase in glucose concentration to $165 \mathrm{mg} / \mathrm{dl}$ had no further effect ( $P$ $=0.41$ and 0.38 ) on disappearance at either insulin dose (low: $14.2 \pm 0.8$ to $18.2 \pm 1.1$ to $18.7 \pm 2.4 \mu \mathrm{mol} \cdot \mathrm{kg}^{-1}$. $\mathrm{min}^{-1}$; high: $21.0 \pm 3.2$ to $33.9 \pm 6.4$ to $32.5 \pm 8.0 \mu \mathrm{mol}$. $\mathrm{kg}^{-1} \cdot \mathrm{min}^{-1}$ for 95,130 , and $165 \mathrm{mg} / \mathrm{dl}$, respectively). We conclude that whereas glucose-induced stimulation of its
\end{abstract}

From the Endocrine Research Unit (R.B., S.W., R.A.R.), Mayo Clinic, Rochester, Minnesota; the Department of Medicine M (M.F.N.), Aarhus Kommunehospital, Aarhus, Denmark; the San Raffaele Scientific Institute (A.C.), Milan; and the Department of Electronics and Informatics (C.C.), the University of Padua, Padua, Italy.

Address correspondence and reprint requests to Dr. Robert A. Rizza, Endocrine Research Unit, Mayo Clinic, 200 First St. S.W., Rochester, MN 55905. E-mail: rizza.robert@mayo.edu.

Received for publication 5 March 1998 and accepted in revised form 8 J uly 1998.

ANOVA, analysis of variance; FFA, free fatty acid; G-6-P, glucose-6-phosphate; $S_{G}$, glucose effectiveness; $S_{1}$, insulin sensitivity index. own uptake is abnormal in type 2 diabetes, glucoseinduced suppression of endogenous glucose production and output is not. The abnormality in uptake occurs in the presence of both basal and high insulin concentrations and is evident at glucose concentrations above but not below $130 \mathrm{mg} / \mathrm{dl}$, implying a defect in a glucoseresponsive step. Diabetes 47:1735-1747, 1998

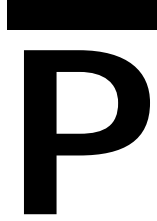

eople with poorly controlled type 2 diabetes have inappropriately high rates of glucose production and inappropriately low rates of glucose disposal (1-3). B oth are regulated by the prevailing insulin and glucose concentrations (4-9). While there is general agreement that type 2 diabetes is associated with insulin resistance (9-12), it is less clear whether glucose effectiveness (defined as the ability of glucose to stimulate its own uptake and to suppress its own release) is al so impaired. In the past, many investigators have used the so-called minimal model (13) to assess glucose effectiveness in diabetic patients (14-18). These experiments, in general, have reported that $S_{G}$ (defined as glucose effectiveness in the presence of basal insulin concentrations) is decreased in type 2 diabetes $(14-16,18)$. However, it has recently become evident that while the minimal model yields a useful estimate of insulin action (referred to as the insulin sensitivity index or $\mathrm{S}_{1}$ ), its ability to accurately assess glucose effectiveness is open to question (19-21). In addition, the minimal model merely measures net glucose effectiveness and net insulin action. It therefore cannot determine whether changes in $\mathrm{S}_{\mathrm{G}}$ or $\mathrm{S}_{\mathrm{I}}$ are due to alterations in glucose production, glucose utilization, or a combination of both.

Several alternative approaches have been used in an effort to circumvent these limitations. We initially attempted to measure insulin action and glucose effectiveness during insulin infusions that mimicked postprandial peripheral insulin concentrations (22). Glucose concentrations were clamped at euglycemic levels or varied so as to reproduce a pattern resembling that normally observed in nondiabetic individuals after food ingestion. Results obtained during the euglycemic experiments were used as a measure of insulin action. Glucose effectiveness was calculated by subtracting the rates of glucose production and utilization observed during the euglycemic experiments from those observed during 
the hyperglycemic experiments. Insulin action measured in this manner was impaired in the diabetic subjects, while glucose effectiveness was normal (22). However, those experiments examined glucose effectiveness in the presence of high insulin concentrations, whereas the previous experiments using the minimal model examined glucose effectiveness in the presence of basal insulin concentrations. We therefore performed additional experiments in which glucose effectiveness was assessed by measuring the glycemic excursion observed when fixed amounts of labeled and unlabeled glucose were infused in the presence of individually determined basal insulin concentrations (23). Those experiments indicated that the ability of glucose to stimulate its own uptake in the presence of basal insulin concentrations was impaired in type 2 diabetes (23). This conclusion was confirmed in other studies using either the glucose clamp technique (24) or the so-called hot minimal model in which tracer and cold glucose are injected concurrently (25).

We were puzzled by the above findings because they seemed to imply that, despite the presence of insulin resistance, high insulin levels somehow reversed a defect in the ability of glucose to stimulate its own uptake. Alternatively, the apparent differences between studies could have been due to differences in methods used to assess glucose effectiveness, differences in subject characteristics, or chance alone. In addition, our earlier studies were not conclusive as to whether the hepatic response to glucose was also abnormal. Glucose infusion in the presence of basal insulin concentrations suppressed glucose production in both diabetic and nondiabetic subjects. How ever, glucose concentrations differed between groups and production did not return to basal in those studies, making it difficult to determine whether the degree of suppression was truly appropriate in the diabetic subjects (23).

The present studies, therefore, were undertaken to address these questions. Specifically, we sought to test the hypotheses that glucose-induced suppression of production and glucose-induced stimulation of uptake are impaired in type 2 diabetes. We further hypothesized that the defect in glucose-induced stimulation of uptake would be evident at low but not high insulin concentrations. We report that both of these hypotheses are incorrect. Although glucose-induced stimulation of uptake is impaired in people with type 2 diabetes, glucose-induced suppression of glucose production (measured with $\left[6-{ }^{3} \mathrm{H}\right]$ glucose) and total glucose output (measured with $\left[2-{ }^{3} \mathrm{H}\right]$ glucose) are not. Furthermore, the defect in glucose-induced stimulation of glucose uptake occurs at both low and high insulin concentrations. How ever, the severity of the defect is dependent on the prevailing glucose concentration, only becoming evident at glucose concentrations above $130 \mathrm{mg} / \mathrm{dl}$, implying saturation of a glucoseresponsive step.

\section{RE SE ARCH DE SIGN AND METHODS}

Subjects. After approval from the Mayo Institutional Review Board, 10 healthy nondiabetic subjects and 9 subjects with type 2 diabetes gave written consent to participate in the study. All diabetic subjects were taking sulfonylureas. These agents were discontinued 3 weeks before study. All subjects were in good health, had normal blood pressure, and were at stable weight. None regularly engaged in vigorous exercise or regularly took medications other than sulfonylureas. Except for one subject, who was adopted, a family history was obtained in all study subjects. None of the nondiabetic subjects had a family history of diabetes in their first-degree relatives. The characteristics of the subjects are shown in Table 1. Age, sex, total body weight, BMI, lean body mass, total body fat, and percent visceral
TABLE 1

Subject characteristics

\begin{tabular}{lcc}
\hline Characteristics & Diabetic & Nondiabetic \\
\hline Age (years) & $56 \pm 2.9$ & $53 \pm 2.4$ \\
Sex (M/F) & $5 / 4$ & $5 / 5$ \\
Total body w eight (kg) & $78 \pm 5.5$ & $82 \pm 3.0$ \\
BMI (kg/m²) & $26 \pm 1.6$ & $29 \pm 1.4$ \\
Lean body mass (kg) & $51 \pm 3.7$ & $49 \pm 3.7$ \\
Total body fat (kg) & $22 \pm 2.9$ & $26 \pm 3.4$ \\
Visceral fat (\%) & $36 \pm 3.6$ & $35 \pm 4.2$ \\
GHb (\%) & $10.2 \pm 0.8$ & $5.4 \pm 0.2$ \\
Fasting glucose (mmol/l) & $10.1 \pm 0.7$ & $4.9 \pm 0.1$
\end{tabular}

Data are means \pm SE

fat did not differ between groups. The fasting glucose concentration and the mean $\mathrm{GHb}$ concentrations (GlycAffin; Isolab, Akron, $\mathrm{OH}$ ) (normal range 4-7\%) were higher in the diabetic than in the nondiabetic subjects.

Experimental design. Subjects were admitted to the Mayo Clinic General Clinical Research Center at 1700 on the evening before each study. A standard 10 $\mathrm{kcal} / \mathrm{kg}$ meal (50\%carbohydrate, $15 \%$ protein, 35\% fat) was eaten between 1730 and 1800. An 18-gauge catheter was inserted into a forearm vein and used for all infusions. The diabetic subjects were infused with insulin (100 U regular human insulin in $1 \mathrm{~L}$ of $0.9 \%$ saline containing $0.4 \mathrm{ml} 25 \%$ human albumin) during the night, while nondiabetic subjects were infused with saline. The insulin infusion was adjusted in the diabetic subjects so as to maintain the glucose concentration at $\sim 5$ $\mathrm{mmol} / \mathrm{l}$ throughout the night (26). A cannula was inserted retrogradely into a dorsal hand vein at 0600 . The hand was then placed in a heated Plexiglas box and maintained at a temperature of $\sim 55^{\circ} \mathrm{C}$ to allow sampling of arterialized venous blood.

An intravenous infusion containing somatostatin $\left(94 \mathrm{ng} \cdot \mathrm{kg}^{-1} \cdot \mathrm{min}^{-1}\right)$, glucagon $\left(1.0 \mathrm{ng} \cdot \mathrm{kg}^{-1} \cdot \mathrm{min}^{-1}\right)$, and growth hormone $\left(4.7 \mathrm{ng} \cdot \mathrm{kg}^{-1} \cdot \mathrm{min}^{-1}\right)$ was begun in all subjects at 0600 (-240 $\mathrm{min}$ ) the following morning. An intravenous infusion of insulin was also started in nondiabetic subjects at a rate of $0.24 \mathrm{mU} \cdot \mathrm{kg}^{-1} \cdot \mathrm{min}^{-1}$, whereas the variable insulin infusion was continued in the diabetic subjects. Plasma glucose concentrations were measured at 15-min intervals using a glucose oxidase method (Beckman Instruments, Brea, CA), and the insulin infusion rate was adjusted in both groups to maintain glucose at $\sim 5 \mathrm{mmol} / \mathrm{l}$. The last adjustment in this "basal" insulin infusion was made at least 30 min before starting the study. The basal insulin infusion (referred to as the low-dose insulin infusion) was terminated at $180 \mathrm{~min}$ and replaced by a $0.78 \mathrm{mU} \cdot \mathrm{kg}^{-1} \cdot \mathrm{min}^{-1}$ insulin infusion (referred to as the high-dose insulin infusion), which was continued until $360 \mathrm{~min}$.

A primed continuous ( $110 \mu \mathrm{Ci}$ prime, $1.10 \mu \mathrm{Ci} /$ min continuous) infusion of $\mathrm{NaH}^{14} \mathrm{CO}_{3}$ was started at 0600 , and primed continuous infusions of $\left[2-{ }^{3} \mathrm{H}\right] \mathrm{glucose}$ and [6- ${ }^{-} \mathrm{H}$ ]glucose (both $17 \mu \mathrm{Ci}$ prime, $0.17 \mu \mathrm{Ci} / \mathrm{min}$ continuous) were started at 0700. All subjects were studied on three occasions, with the order of study being random. Beginning at time zero, sufficient glucose (as dextrose) was infused to maintain the glucose concentration at $\sim 95 \mathrm{mg} / \mathrm{dl}(5 \mathrm{mmol} / \mathrm{l}), \sim 130 \mathrm{mg} / \mathrm{dl}(7.3 \mathrm{mmol} / \mathrm{l})$, or $\sim 165$ $\mathrm{mg} / \mathrm{dl}(9.3 \mathrm{mmol} / \mathrm{l})$. All infused glucose contained both $\left[2{ }^{-3} \mathrm{H}\right] \mathrm{glucose}$ and $\left[6{ }^{3} \mathrm{H}\right] \mathrm{glu}$ cose in an effort to minimize the change in plasma glucose specific activity during the study (27). In addition, the rates of the continuous infusions of $\left[2-{ }^{3} \mathrm{H}\right] \mathrm{glu}$ cose and $\left[6-{ }^{3} \mathrm{H}\right]$ glucose were maintained at $100 \%$ from 0 to $180 \mathrm{~min}$ on the 95 $\mathrm{mg} / \mathrm{dl}$ study day, decreased by $50 \%$ on the $130 \mathrm{mg} / \mathrm{dl}$ study day, and decreased by $75 \%$ on the $165 \mathrm{mg} / \mathrm{dl}$ study day. At $180 \mathrm{~min}$, the tracer infusion rates were further decreased from the 0 - to 180 -min tracer infusion rates according to the anticipated decrease in endo genous glucose production during the insulin infusion (23). In the nondiabetic subjects, the rates were decreased by a further $16 \%$ from 180 to 195 $\mathrm{min}, 29 \%$ from 195 to $210 \mathrm{~min}, 40 \%$ from 210 to $225 \mathrm{~min}, 47 \%$ from 225 to $240 \mathrm{~min}$, $57 \%$ from 240 to $270 \mathrm{~min}, 65 \%$ from 270 to $300 \mathrm{~min}, 70 \%$ from 300 to $330 \mathrm{~min}$, and $75 \%$ from 330 to $360 \mathrm{~min}$. In the diabetic subjects, the rates were decreased by a further $8 \%$ from 180 to $195 \mathrm{~min}, 15 \%$ from 195 to $210 \mathrm{~min}$, $22 \%$ from 210 to $225 \mathrm{~min}$, $27 \%$ from 225 to $240 \mathrm{~min}, 37 \%$ from 240 to $270 \mathrm{~min}, 44 \%$ from 270 to $300 \mathrm{~min}, 50 \%$ from 300 to $330 \mathrm{~min}$, and 53\% from 330 to $360 \mathrm{~min}$. Arterialized venous blood was sampled at regular intervals for measurement of glucose and hormone concentrations as well as glucose specific activity. Breath was also collected to permit measurement of ${ }^{14} \mathrm{CO}_{2}$ specific activity as previously described (28).

Analytical techniques. Arterialized plasma samples were placed on ice, centrifuged at $4^{\circ} \mathrm{C}$, separated, and stored at $-20^{\circ} \mathrm{C}$ until assay. Plasma insulin, C-peptide, and glucagon concentrations were measured by radioimmunoassay using reagents purchased from Linco Research (St. Louis, MO). Plasma growth hormone concentration was measured using reagents provided by ICN Biomedicals (Costa Mesa, CA). Plasma [2- $\left.{ }^{3} \mathrm{H}\right]$ glucose and $\left[6-{ }^{3} \mathrm{H}\right]$ glucose specific activities were deter- 

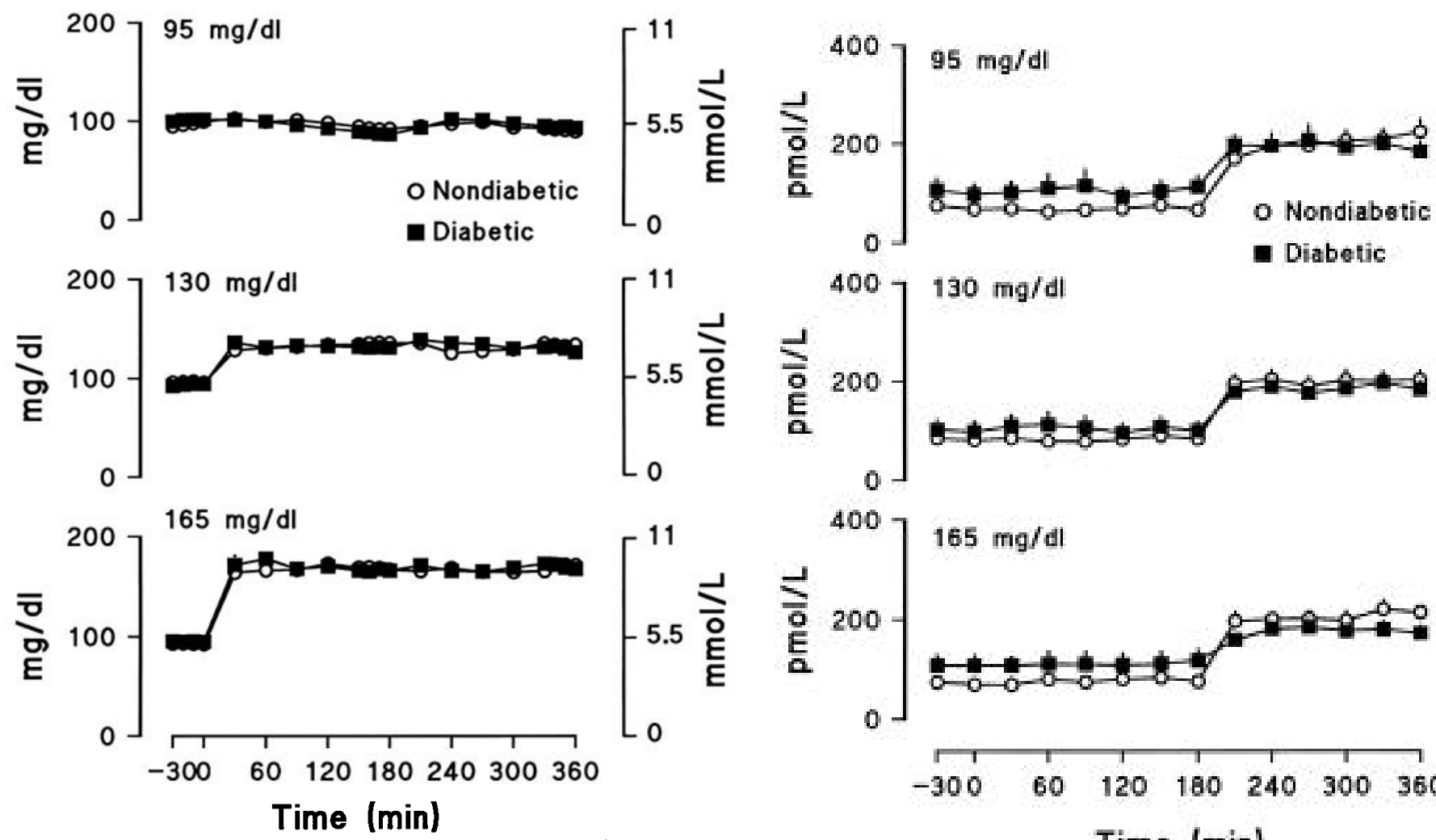

FIG. 1. Glucose concentrations observed in the diabetic and nondiabetic subjects when glucose was either clamped at $\sim 95 \mathrm{mg} / \mathrm{dl}$ throughout the experiment or acutely increased at time zero to $\sim 130$ or $\sim 165$ $\mathrm{mg} / \mathrm{dl}$. The insulin infusion was maintained at a constant "basal" rate (referred to as the low-dose insulin infusion) from 0 to $180 \mathrm{~min}$ at which time it was increased to a rate of $0.79 \mathrm{mU} \cdot \mathrm{kg}^{-1} \cdot \mathrm{min}^{-1}$ (referred to as the high-dose insulin infusion).

mined by selective enzymatic detritiation as previously described (29). Body composition and lean body mass were measured by dual-energy X-ray absorptiometry (DPX scanner; Lunar, Madison, WI). Percentage of intra-abdominal adiposity was determined using a single-slice computerized tomograph scan at the level of L2/L3 (30). Glucose concentrations were measured using a Yellow Springs glucose analyzer (Yellow Springs Instruments, Yellow Springs, $\mathrm{OH}$ ). Plasma free fatty acids (FFAs) were measured enzymatically using a Wako NEFA C kit (Wako Chemicals, Richmond, VA).

Calculations. Glucose specific activities were smoothed using the method of Bradley et al. (31). Glucose appearance and disappearance were calculated using Steele's non-steady-state equations (32). The volume of distribution of glucose was assumed to equal $200 \mathrm{ml} / \mathrm{kg}$, and the pool correction factor was assumed to be 0.65 $(33,34)$. Endogenous glucose production and total glucose output were determined by subtracting the glucose infusion rate from the tracer-determined rate of glucose appearance. $\left[6-{ }^{3} \mathrm{H}\right]$ glucose was used to trace the rate of endogenous glucose production, and $\left[2{ }^{3} \mathrm{H}\right]$ glucose was used to trace total glucose output (35-37). Hepatic glucose cycling was calculated by subtracting results obtained with [6${ }^{3} \mathrm{H}$ ]glucose from those obtained with $\left[2-{ }^{3} \mathrm{H}\right]$ glucose $(35-37)$. All rates of infusion and turnover are expressed per kilogram of lean body mass. The percent glucose derived from ${ }^{14} \mathrm{CO}_{2}$ was calculated by dividing the plasma $\left[{ }^{14} \mathrm{C}\right]$ glucose specific activity by breath ${ }^{14} \mathrm{CO}_{2}$ specific activity (28).

Statistical analysis. Data in the figures and text are expressed as means $\pm \mathrm{SE}$. Values observed from -30 to 0 min on the 3 study days were meaned in each individual in order to test for baseline differences. Analysis of variance (ANOVA) for repeated measures was used to determine whether results differed on the 3 study days (i.e., 95, 130, and $165 \mathrm{mg} / \mathrm{dl}$ ). Paired Student's t test was used to test for within-group differences. Nonpaired Student's ttest and, when appropriate, MannWhitney rank-sum tests were used to test for between-group differences. One-sided Student's t test was used to test the hypotheses that an increase in insulin or glucose concentration suppresses glucose production and stimulates glucose disappearance and that these effects are impaired in people with diabetes. All other tests were two-sided. A P value $<0.05$ was considered statistically significant.

\section{RESULTS}

Glucose, insulin, C-peptide, glucagon, and growth hormone concentrations. Basal (-30 to $0 \mathrm{~min}$ ) glucose concentrations were stable and equal in the diabetic and nondiabetic subjects on the 3 study days (Fig. 1). Glucose concentrations during the euglycemic and hyperglycemic portions of the studies also did not differ in the diabetic and nondiabetic subjects, averaging, respectively, $4.88 \pm 0.18$ vs. $5.15 \pm 0.25,7.3$ \pm 0.17 vs. $7.53 \pm 0.16$, and $9.23 \pm 0.32$ vs. $9.36 \pm 0.17 \mathrm{mmol} / \mathrm{l}$ during the final $30 \mathrm{~min}$ (150-180 $\mathrm{min}$ ) of the low-dose insulin infusions and $5.22 \pm 0.13$ vs. $5.07 \pm 0.11,7.23 \pm 0.18$ vs. $7.44 \pm$ 0.10 , and $9.46 \pm 0.30$ vs. $9.45 \pm 0.26 \mathrm{mmol} / \mathrm{l}$ during the final 30 $\min (330-360 \mathrm{~min}$ ) of the high-dose insulin infusions.

The diabetic subjects were infused with insulin during the night so that glucose concentrations would be equivalent in both groups at the start of each study. This resulted in slightly, but not significantly, higher $(P=0.23)$ basal $(-30$ to $0 \mathrm{~min}$ ) insulin concentrations in the diabetic than in the nondiabetic subjects ( $103 \pm 22$ vs. $75 \pm 10 \mathrm{pmol} / \mathrm{l})$. Because these "basal" insulin concentrations were maintained until $180 \mathrm{~min}$, insulin concentrations during the low-dose insulin infusions remained slightly higher ( $108 \pm 23 \mathrm{vs} .76 \pm 9 \mathrm{pmol} / \mathrm{l} ; \mathrm{P}=0.19$ ) in the diabetic than in the nondiabetic subjects (Fig. 2). Insulin concentrations during the high-dose insulin infusions also did not differ between the two groups (196 \pm 17 vs. 201 $\pm 20 \mu \mathrm{U} / \mathrm{ml}$ ). 
TABLE 2

Plasma glucagon and C-peptide concentrations when glucose concentration was maintained at 95, 135, and 165 mg/dl

\begin{tabular}{|c|c|c|c|c|c|c|c|c|c|c|c|c|c|}
\hline & $0 \mathrm{~min}$ & $30 \mathrm{~min}$ & $60 \mathrm{~min}$ & $90 \mathrm{~min}$ & $120 \mathrm{~min}$ & $150 \mathrm{~min}$ & $180 \mathrm{~min}$ & $210 \mathrm{~min}$ & $240 \mathrm{~min}$ & $270 \mathrm{~min}$ & $300 \mathrm{~min}$ & $330 \mathrm{~min}$ & $360 \mathrm{~min}$ \\
\hline \multicolumn{14}{|l|}{ Glucagon (pg/ml) } \\
\hline \multicolumn{14}{|l|}{$95 \mathrm{mg} / \mathrm{dl}$} \\
\hline Diabetic & $78.7 \pm 4.5$ & $78.6 \pm 4.6$ & $74.8 \pm 4.6$ & $76.0 \pm 5.4$ & $75.6 \pm 4.6$ & $77.0 \pm 4.8$ & $77.0 \pm 5.3$ & $82.2 \pm 5.6$ & $78.0 \pm 4.9$ & $78.7 \pm 4.6$ & $79.0 \pm 4.7$ & $77.4 \pm 4.8$ & $78.7 \pm 7.2$ \\
\hline Nondiabetic & $78.8 \pm 5.8$ & $77.5 \pm 6.5$ & $74.6 \pm 5.9$ & $77.4 \pm 5.9$ & $74.5 \pm 5.8$ & $76.3 \pm 6.8$ & $77.3 \pm 6.9$ & $73.0 \pm 5.9$ & $74.5 \pm 5.8$ & $73.1 \pm 7.4$ & $77.8 \pm 6.6$ & $75.0 \pm 5.8$ & $78.3 \pm 7.0$ \\
\hline \multicolumn{14}{|l|}{$130 \mathrm{mg} / \mathrm{dl}$} \\
\hline Diabetic & $80.4 \pm 5.6$ & $79.6 \pm 6.0$ & $83.0 \pm 4.4$ & $84.0 \pm 6.1$ & $84.1 \pm 6.5$ & $79.9 \pm 5.6$ & $82.0 \pm 3.7$ & $80.2 \pm 5.7$ & $79.4 \pm 5.6$ & $78.7 \pm 4.8$ & $79.8 \pm 4.4$ & $83.2 \pm 4.4$ & $75.8 \pm 5.3$ \\
\hline Nondiabetic & $81.9 \pm 10.0$ & $82.8 \pm 8.9$ & $81.1 \pm 8.9$ & $81.2 \pm 8.3$ & $83.5 \pm 7.3$ & $80.5 \pm 7.0$ & $84.3 \pm 8.3$ & $83.9 \pm 9.6$ & $83.7 \pm 9.0$ & $79.4 \pm 9.6$ & $83.6 \pm 9.7$ & $80.1 \pm 9.3$ & $81.0 \pm 10.7$ \\
\hline \multicolumn{14}{|l|}{$165 \mathrm{mg} / \mathrm{dl}$} \\
\hline Diabetic & $79.8 \pm 8.5$ & $76.0 \pm 8.0$ & $75.7 \pm 7.7$ & $74.9 \pm 7.3$ & $77.2 \pm 5.8$ & $78.2 \pm 7.9$ & $80.3 \pm 7.0$ & $76.2 \pm 8.4$ & $77.0 \pm 8.2$ & $75.3 \pm 7.3$ & $76.6 \pm 8.1$ & $80.1 \pm 7.9$ & $77.6 \pm 8.8$ \\
\hline Nondiabetic & $80.3 \pm 5.7$ & $77.1 \pm 5.8$ & $75.0 \pm 2.9$ & $76.1 \pm 5.1$ & $76.9 \pm 4.5$ & $77.9 \pm 6.2$ & $75.0 \pm 5.9$ & $71.7 \pm 5.8$ & $76.9 \pm 5.9$ & $74.6 \pm 5.4$ & $74.2 \pm 5.6$ & $73.6 \pm 6.0$ & $71.7 \pm 5.0$ \\
\hline \multicolumn{14}{|l|}{ C-peptide (nmol/l) } \\
\hline \multicolumn{14}{|l|}{$95 \mathrm{mg} / \mathrm{dl}$} \\
\hline Diabetic & $0.03 \pm 0.00$ & $0.03 \pm 0.00$ & $0.03 \pm 0.00$ & $0.03 \pm 0.01$ & $0.03 \pm 0.00$ & $0.03 \pm 0.00$ & $0.03 \pm 0.00$ & $0.03 \pm 0.01$ & $0.03 \pm 0.00$ & $0.03 \pm 0.00$ & $0.03 \pm 0.00$ & $0.03 \pm 0.004$ & $0.03 \pm 0.004$ \\
\hline Nondiabetic & $0.06 \pm 0.00$ & $0.06 \pm 0.01$ & $0.06 \pm 0.00$ & $0.06 \pm 0.01$ & $0.05 \pm 0.01$ & $0.05 \pm 0.01$ & $0.04 \pm 0.01$ & $0.04 \pm 0.01$ & $0.04 \pm 0.00$ & $0.04 \pm 0.01$ & $0.04 \pm 0.01$ & $0.04 \pm 0.004$ & $0.04 \pm 0.004$ \\
\hline \multicolumn{14}{|l|}{$130 \mathrm{mg} / \mathrm{dl}$} \\
\hline Diabetic & $0.03 \pm 0.00$ & $0.03 \pm 0.00$ & $0.03 \pm 0.00$ & $0.02 \pm 0.00$ & $0.02 \pm 0.00$ & $0.03 \pm 0.01$ & $0.02 \pm 0.00$ & $0.02 \pm 0.00$ & $0.02 \pm 0.00$ & $0.03 \pm 0.00$ & $0.02 \pm 0.00$ & $0.02 \pm 0.003$ & $0.03 \pm 0.004$ \\
\hline Nondiabetic & $0.05 \pm 0.01$ & $0.06 \pm 0.01$ & $0.05 \pm 0.01$ & $0.05 \pm 0.01$ & $0.05 \pm 0.01$ & $0.07 \pm 0.02$ & $0.06 \pm 0.01$ & $0.05 \pm 0.01$ & $0.05 \pm 0.01$ & $0.05 \pm 0.01$ & $0.05 \pm 0.01$ & $0.05 \pm 0.006$ & $0.04 \pm 0.004$ \\
\hline \multicolumn{14}{|l|}{$165 \mathrm{mg} / \mathrm{dl}$} \\
\hline Diabetic & $0.03 \pm 0.01$ & $0.04 \pm 0.01$ & $0.03 \pm 0.01$ & $0.04 \pm 0.00$ & $0.03 \pm 0.01$ & $0.03 \pm 0.01$ & $0.03 \pm 0.01$ & $0.03 \pm 0.01$ & $0.03 \pm 0.01$ & $0.03 \pm 0.01$ & $0.03 \pm 0.01$ & $0.03 \pm 0.006$ & $0.03 \pm 0.006$ \\
\hline Nondiabetic & $0.04 \pm 0.00$ & $0.05 \pm 0.00$ & $0.12 \pm 0.11$ & $0.08 \pm 0.01$ & $0.09 \pm 0.01$ & $0.12 \pm 0.01$ & $0.10 \pm 0.01$ & $0.09 \pm 0.01$ & $0.10 \pm 0.01$ & $0.11 \pm 0.02$ & $0.11 \pm 0.02$ & $0.15 \pm 0.008$ & $0.12 \pm 0.009$ \\
\hline
\end{tabular}

Data are means $\pm \mathrm{SE}$.

C-peptide concentrations were suppressed both before and during the clamps in both groups (Table 2). How ever, Cpeptide increased slightly, but significantly, in the nondiabetic subjects when glucose was raised from 95 to 130 to 165 $\mathrm{mg} / \mathrm{dl}$ during both the low-dose $(P=0.04)$ and high-dose $(P$ $=0.004)$ insulin infusions. C-peptide concentrations did not change in the diabetic subjects. Glucagon and growth hormone (data not shown) concentrations remained constant and equal in both groups on all 3 study days (Table 2).

Plasma glucose specific activity. Plasma $\left[6-{ }^{3} \mathrm{H}\right] \mathrm{glucose}$ (Fig. $3 \mathrm{~A}$ ) and $\left[2{ }^{3} \mathrm{H}\right]$ glucose (Fig. $3 \mathrm{~B}$ ) specific activities were maintained within $15 \%$ of basal values in both groups on all 3 study days.

Endogenous glucose production and total glucose output. Both $\left[6^{-}{ }^{3} \mathrm{H}\right]$ glucose and $\left[2-{ }^{3} \mathrm{H}\right]$ glucose were infused, since the two tracers assess different aspects of glucose metabolism. $\left[2-{ }^{3} \mathrm{H}\right]$ glucose, but not $\left[6-{ }^{3} \mathrm{H}\right]$ glucose, is extensively detritiated during equilibration with the hepatic (and perhaps renal) glucose-6-phosphate (G-6-P) pool (35). Therefore $\left[2-{ }^{3} \mathrm{H}\right]$ glucose taken up by the liver then subsequently released back into the systemic circulation will no longer be labeled. Thus, $\left[6-{ }^{3} \mathrm{H}\right] \mathrm{glucose}$ measures endogenous glucose production, whereas $\left[2-{ }^{3} \mathrm{H}\right] \mathrm{glucose}$ measures total glucose output.

$\mathrm{B}$ asal (-30 to $0 \mathrm{~min}$ ) rates of endogenous glucose production (Fig. 4A) and total glucose output (Fig. 4B) were comparable on the 3 study days in both groups. Rates in the diabetic subjects did not differ from those in the nondiabetic subjects. Endogenous glucose production and total glucose output fell slowly during the low-dose insulin infusion (i.e., from 0 to $180 \mathrm{~min}$ ) in both the diabetic and nondiabetic subjects when plasma glucose concentration was maintained at $95 \mathrm{mg} / \mathrm{dl}$, presumably because of an increasing duration of fast. In contrast, an increase in glucose concentration at time zero to either 130 or $165 \mathrm{mg} / \mathrm{dl}$ resulted in a prompt decrease in endogenous glucose production and total glucose output in both groups. Dose-response curves (Fig. 5A and B) were constructed by plotting the mean rates of glucose production and output during the final $30 \mathrm{~min}$ (150-180 $\mathrm{min}$ ) of the lowdose insulin infusion versus the prevailing plasma glucose concentration. These curves demonstrated that an increase in glucose from 95 to 130 to $165 \mathrm{mg} / \mathrm{dl}$ caused a parallel decrease ( $P=0.001-0.002$ by ANOVA) in both endogenous glucose production and total glucose output in both the diabetic and nondiabetic subjects.

Endogenous glucose production and total glucose output were further suppressed when the insulin infusion rate was increased at $180 \mathrm{~min}$ (Fig. 4). Endogenous glucose production was greater $(P=0.05)$ in the diabetic than nondiabetic groups during the $95 \mathrm{mg} / \mathrm{dl}$ study, but it did not differ during the 130 and $165 \mathrm{mg} / \mathrm{dl}$ studies. Because of already low rates, glucose production in the nondiabetic subjects did not suppress further as glucose was raised from 95 to 130 to $165 \mathrm{mg} / \mathrm{dl}$ (Fig. 5C). In contrast, glucose production in the diabetic subjects further decreased ( $P=0.02$ by ANOVA) when glucose was increased. Total glucose output was comparably suppressed in both groups during the high-dose insulin infusion, and it did not differ in the diabetic and nondiabetic subjects on any of the 3 study days (Fig. 5D). Hepatic glucose cycling (calculated by subtracting endogenous glucose production from total glucose output) also did not differ between the groups on any of the 3 study days (Table 3 ).

Incorporation of ${ }^{14} \mathrm{CO}_{2}$ into glucose. Incorporation of ${ }^{14} \mathrm{CO}_{2}$ into glucose was greater $(\mathrm{P}=0.02)$ in the diabetic than in the nondiabetic subjects in the basal state (Fig. 6). Incorporation of ${ }^{14} \mathrm{CO}_{2}$ into glucose increased from 0 to $180 \mathrm{~min}$ in both groups on the $95 \mathrm{mg} / \mathrm{dl}$ study day, presumably reflecting an increase in the contribution of gluconeogenesis to systemic glucose release due to the increased duration of fast. In contrast, the incorporation of ${ }^{14} \mathrm{CO}_{2}$ into glucose remained constant from 0 to $180 \mathrm{~min}$ on the $130 \mathrm{mg} / \mathrm{dl}$ study day and decreased on the $165 \mathrm{mg} / \mathrm{dl}$ study day. Dose-response curves were constructed by plotting results observed during the final $30 \mathrm{~min}$ of the low-dose insulin infusion versus the prevailing glucose concentration (Fig. 7A). These curves indicated that the percentage of glucose derived from ${ }^{14} \mathrm{CO}_{2}$ progressively decreased when glucose concentration was increased 95 to 130 to $165 \mathrm{mg} / \mathrm{dl}$ in both the diabetic $(P=0.001$ by ANOVA) and nondiabetic ( $P=0.003$ by ANOVA) subjects. Incorporation of ${ }^{14} \mathrm{CO}_{2}$ into glucose was slightly higher $(\mathrm{P}=$ 0.06 ) in the diabetic than in the nondiabetic subjects during 


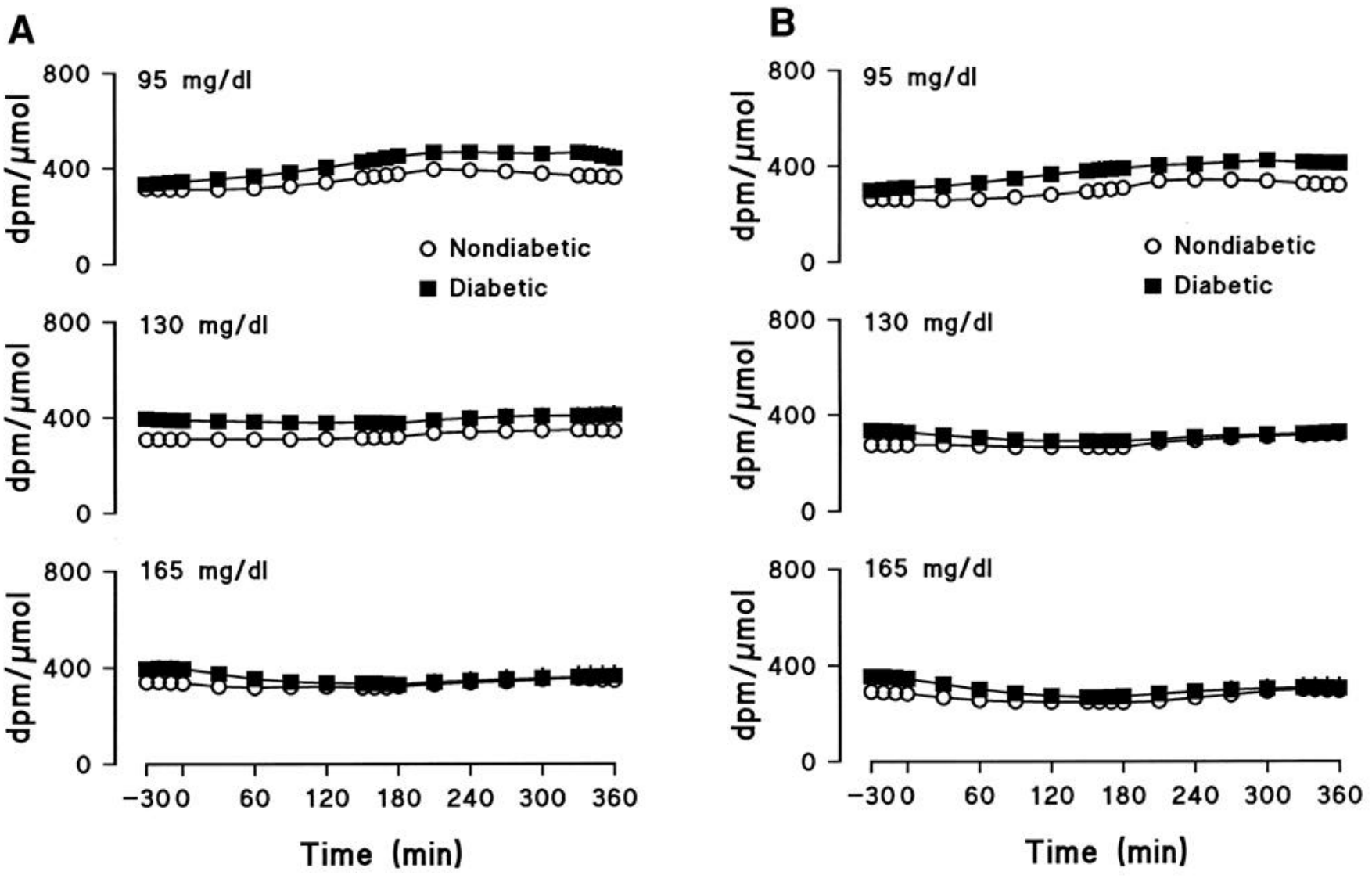

FIG. 3. Plasma $\left[6-{ }^{3} \mathrm{H}\right]$ glucose $(\mathrm{A})$ and $\left[2-{ }^{3} \mathrm{H}\right] \mathrm{glucose}(\mathrm{B})$ specific activities observed in the diabetic and nondiabetic subjects when glucose concentration was either clamped at $\sim 95 \mathrm{mg} / \mathrm{dl}$ throughout the experiment or acutely increased at time zero to either $\sim 130 \mathrm{or} \sim 165 \mathrm{mg} / \mathrm{dl}$. The insulin infusion rate was maintained at a constant "basal" rate (referred to as the low-dose insulin infusion) from 0 to 180 min at which time it was increased to a rate of $0.79 \mathrm{mU} \cdot \mathrm{kg}^{-1} \cdot \mathrm{min}^{-1}$ (referred to as the high-dose insulin infusion).

the low-dose insulin infusion at a glucose concentration of 95 $\mathrm{mg} / \mathrm{dl}$, with the difference becoming less evident when glucose was increased to 130 or $165 \mathrm{mg} / \mathrm{dl}$.

The increase in the insulin infusion rate at 180 min resulted in a decrease in incorporation of ${ }^{14} \mathrm{CO}_{2}$ into glucose in both groups. However, the degree of suppression was less in the diabetic than in the nondiabetic subjects, resulting in the percentage of glucose derived from ${ }^{14} \mathrm{CO}_{2}$ being higher $(\mathrm{P}=$ 0.01-0.001) in the former than the latter on all 3 study days. Hyperglycemia further decreased ( $P=0.001$ by ANOVA) incorporation of ${ }^{14} \mathrm{CO}_{2}$ into glucose in the diabetic subjects but did not alter the already suppressed rates in the nondiabetic subjects (Fig. 7B).

Glucose disappearance. Basal (-30 to $0 \mathrm{~min}$ ) rates of glucose disappearance were comparable on the 3 study days in both groups and did not differ in the diabetic and nondiabetic subjects (Fig. 8). Glucose disappearance changed minimally from 0 to $180 \mathrm{~min}$ on the $95 \mathrm{mg} / \mathrm{dl}$ study day. Disappearance transiently increased in both groups when glucose was acutely raised to 130 or $165 \mathrm{mg} / \mathrm{dl}$. Glucose disappearance during the final 30 min of the low-dose insulin infusion was lower $(P=0.005-0.02)$ in the diabetic than in the nondiabetic subjects on all 3 study days (Figs. 8 and 9). An increase in glucose concentration from 95 to $130 \mathrm{mg} / \mathrm{dl}$ was accompanied by a comparable increase in glucose disappearance in both the diabetic $\left(14.2 \pm 0.8\right.$ to $\left.18.2 \pm 1.1 \mu \mathrm{mol} \cdot \mathrm{kg}^{-1} \cdot \mathrm{min}^{-1}\right)$ and nondiabetic (19.9 \pm 1.8 to $\left.23.6 \pm 1.8 \mu \mathrm{mol} \cdot \mathrm{kg}^{-1} \cdot \mathrm{min}^{-1}\right)$ sub- jects. In contrast, whereas an increase in glucose to 165 $\mathrm{mg} / \mathrm{dl}$ resulted in a further increase $(P=0.02)$ in glucose disappearance in the nondiabetic subjects (to $25.4 \pm 1.6 \mu \mathrm{mol}$. $\left.\mathrm{kg}^{-1} \cdot \mathrm{min}^{-1}\right)$, it did not al ter disappearance in the diabetic subjects (to $18.7 \pm 2.4 \mu \mathrm{mol} \cdot \mathrm{kg}^{-1} \cdot \mathrm{min}^{-1} ; \mathrm{P}=0.41$ ).

Glucose disappearance during the high-dose insulin infusion showed a similar pattern. Glucose disappearance was lower ( $P=0.03-0.001)$ in the diabetic than in the nondiabetic subjects during the final 30 min of the high-dose insulin infusion on all 3 days (Figs. 8 and 9). Once again, an increase in glucose from 95 to $130 \mathrm{mg} / \mathrm{dl}$ was accompanied by a comparable increase in glucose disappearance in both the diabetic $\left(21.0 \pm 3.2\right.$ to $\left.33.9 \mu \mathrm{mol} \cdot \mathrm{kg}^{-1} \cdot \mathrm{min}^{-1}\right)$ and nondiabetic $\left(36.4 \pm 3.1\right.$ to $47.6 \pm 4.5 \mu \mathrm{mol} \cdot \mathrm{kg}^{-1} \cdot \mathrm{min}^{-1}$ ) subjects. Whereas an increase in glucose to $165 \mathrm{mg} / \mathrm{dl}$ resulted in a further increase $(P=0.02)$ in glucose disappearance in the nondiabetic subjects (to $61.1 \pm 7.0 \mu \mathrm{mol} \cdot \mathrm{kg}^{-1} \cdot \mathrm{min}^{-1}$ ), it did not alter glucose disappearance in the diabetic subjects (to $32.5 \pm$ $8.0 \mu \mathrm{mol} \cdot \mathrm{kg}^{-1} \cdot \mathrm{min}^{-1} ; \mathrm{P}=0.37$ ).

Urinary glucose excretion. Urinary glucose excretion on the 95,135 , and $165 \mathrm{mg} / \mathrm{dl}$ study days averaged, respectively, $0.05 \pm 0.02,0.10 \pm 0.04$, and $0.26 \pm 0.12 \mu \mathrm{mol} \cdot \mathrm{kg}^{-1} \cdot \mathrm{min}^{-1}$ in the diabetic subjects and $0.01 \pm 0.00,0.01 \pm 0.00$, and $0.02 \pm$ $0.00 \mu \mathrm{mol} \cdot \mathrm{kg}^{-1} \cdot \mathrm{min}^{-1}$ in the nondiabetic subjects. The rate of urinary glucose excretion was greater $(P=0.03)$ in the diabetic than in the nondiabetic subjects on both the 135 and 165 $\mathrm{mg} / \mathrm{dl}$ study days. 


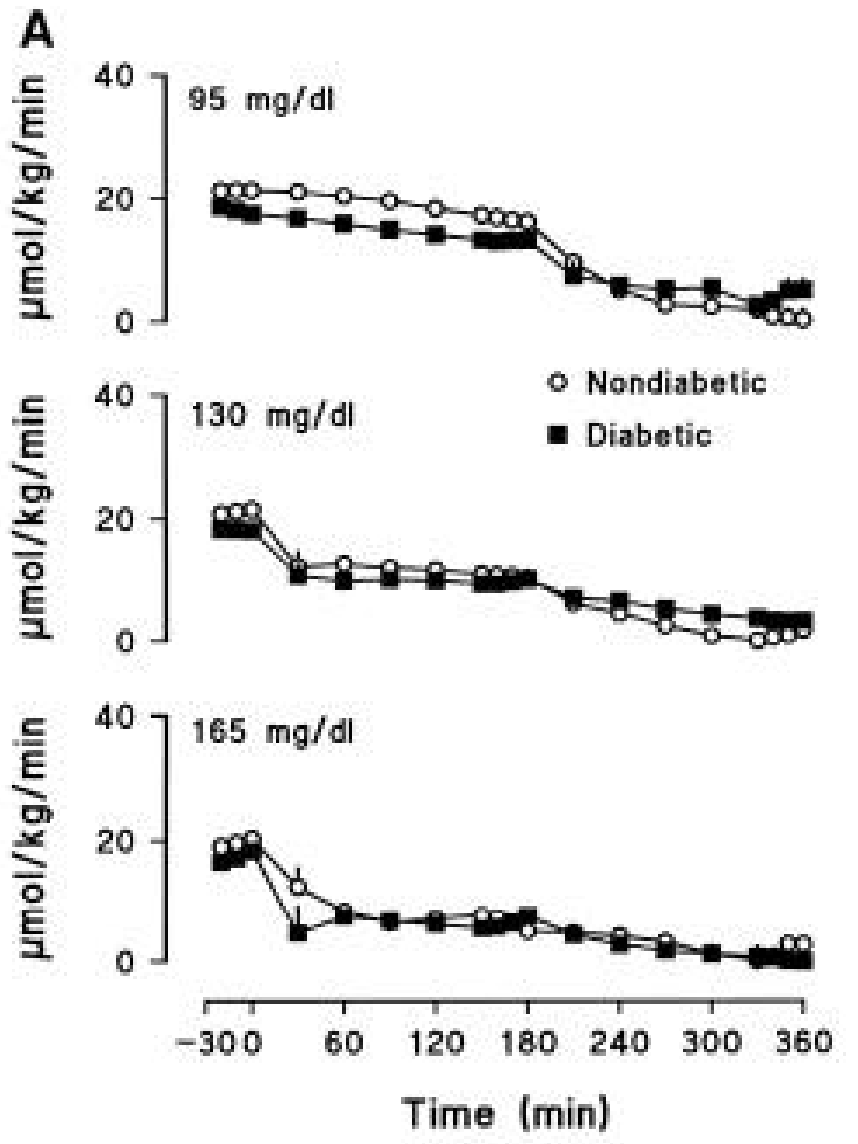

B
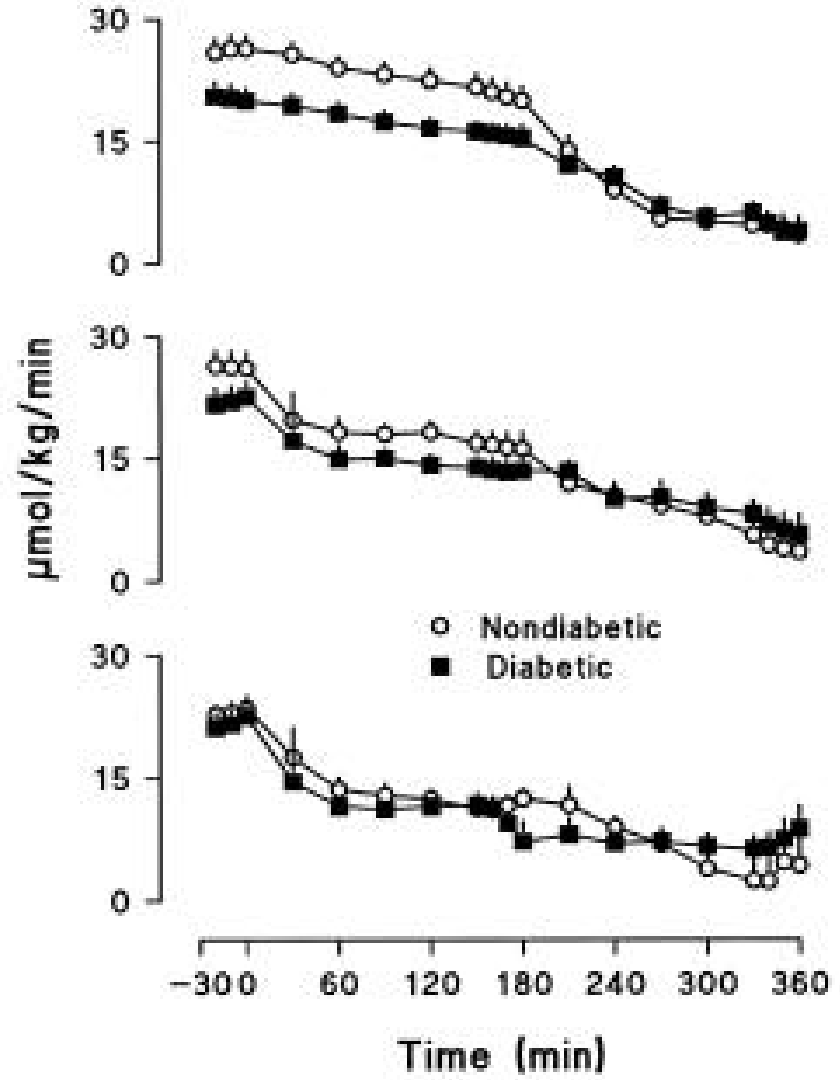

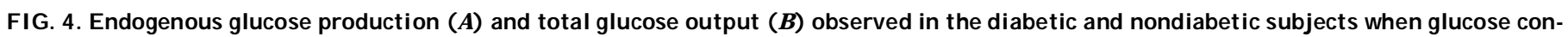
centration was either clamped at $\sim 95 \mathrm{mg} / \mathrm{dl}$ throughout the experiment or acutely increased at time zero to either $\sim 130 \mathrm{or} \sim 165 \mathrm{mg} / \mathrm{dl}$. The insulin infusion rate was maintained at a constant "basal" rate (referred to as the low-dose insulin infusion) from 0 to 180 min at which time it was increased to a rate of $0.79 \mathrm{mU} \cdot \mathrm{kg}^{-1} \cdot \mathrm{min}^{-1}$ (referred to as the high-dose insulin infusion).

Plasma FFA concentrations. Basal ( -30 to 0 min) FFA concentrations were higher $(P=0.01)$ in the diabetic than in the nondiabetic subjects (Fig. 10). Hyperglycemia suppressed FFA concentrations in both the diabetic $(P=0.02$ by ANOVA) and nondiabetic ( $P=0.06$ by ANOVA) subjects during the low-dose insulin infusion. The high insulin infusion suppressed FFAs in both groups; however, concentrations remained higher in the diabetic than in the nondiabetic subjects $(P=0.07,0.03$, and 0.01 , respectively, on the 95,130 , and $165 \mathrm{mg} / \mathrm{dl}$ study days). Hyperglycemia did not further suppress FFA concentration during the high-dose insulin infusion.

\section{DISCUSSION}

People with poorly controlled type 2 diabetes have abnormalities in both glucose production and glucose utilization (1-3). Glucose production is inappropriately high and glucose uptake is inappropriately low for the prevailing glucose and insulin concentrations (1-3). The present studies indicate that insulin-induced suppression but not glucose-induced suppression of glucose release is impaired in type 2 diabetes. Hyperglycemia comparably inhibited glucose release in both groups regardless of whether it was assessed with a tracer ([6${ }^{3} \mathrm{H}$ ]glucose) that measures net glucose production or a tracer $\left(\left[2-{ }^{3} \mathrm{H}\right]\right.$ glucose) that measures total glucose output. Furthermore, hyperglycemia also equally suppressed the rate of incorporation of ${ }^{14} \mathrm{CO}_{2}$ into glucose in both groups, suggesting comparable regulation of gluconeogenesis by glucose. In contrast, glucose-induced stimulation of its ow $n$ uptake is abnormal in type 2 diabetes. This defect is demonstrable in the presence of both basal and suprabasal insulin concentrations and is evident at glucose concentrations above but not below $130 \mathrm{mg} / \mathrm{dl}$, implying saturation of a glucose-responsive step.

E ffects of glucose on glucose release. Both we and others have previously demonstrated that glucose can inhibit its own production $(7,22-24,38)$. However, to the best of our knowledge, the present studies are the first to simultaneously define the glucose dose-response curves for suppression of glucose production and total glucose output in humans. This is likely because methods for accurately measuring glucose production and output at varying glucose levels have only recently become available. Particular care was taken to ensure that glucose specific activity was kept constant throughout the study so as to minimize errors in the measurement of glucose appearance and disappearance $(27,34)$. Only purified tracers were used (39). The euglycemic and hyperglycemic clamps were performed on separate days to preclude falsely ascribing time-dependent changes in turnover to the effects of sequential increases in glucose concentration.

Both Del Prato et al. (24) and Ader et al. (5) have also recently examined the ability of glucose to suppress endogenous glucose production in the presence of basal insulin concentrations. In contrast to the present experiments, the 
A

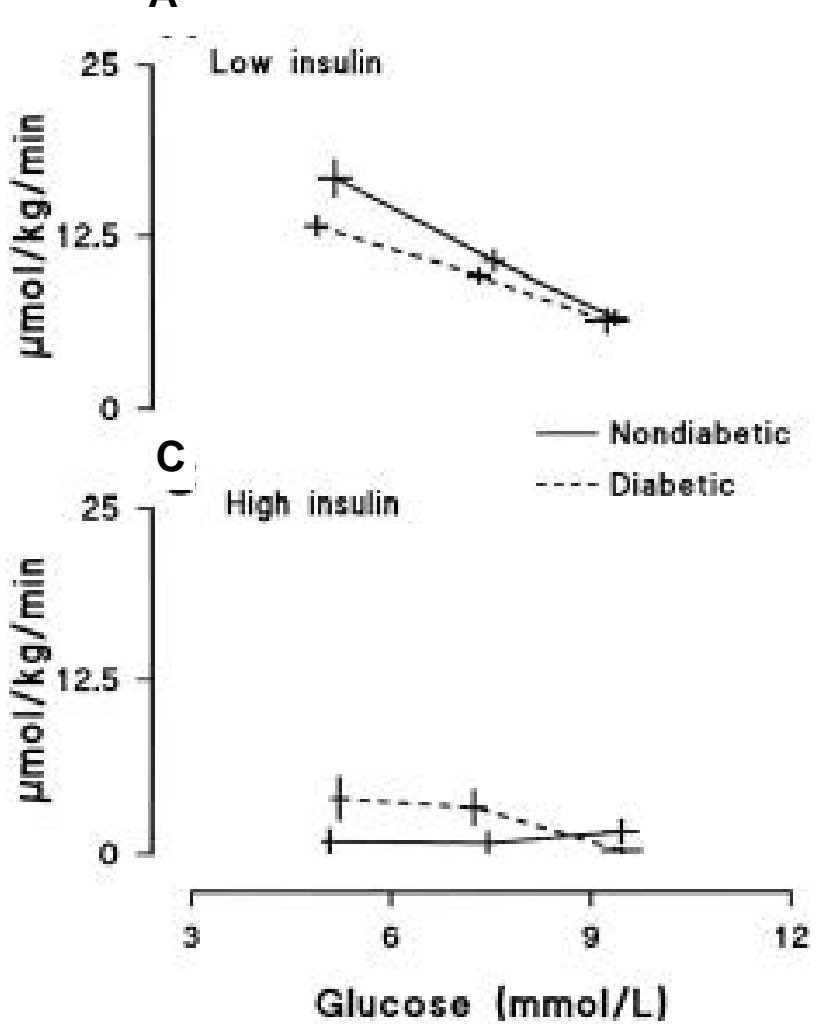

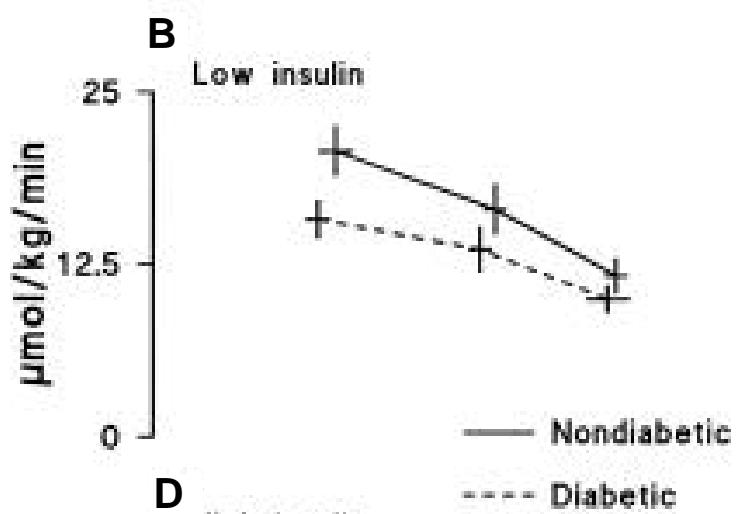

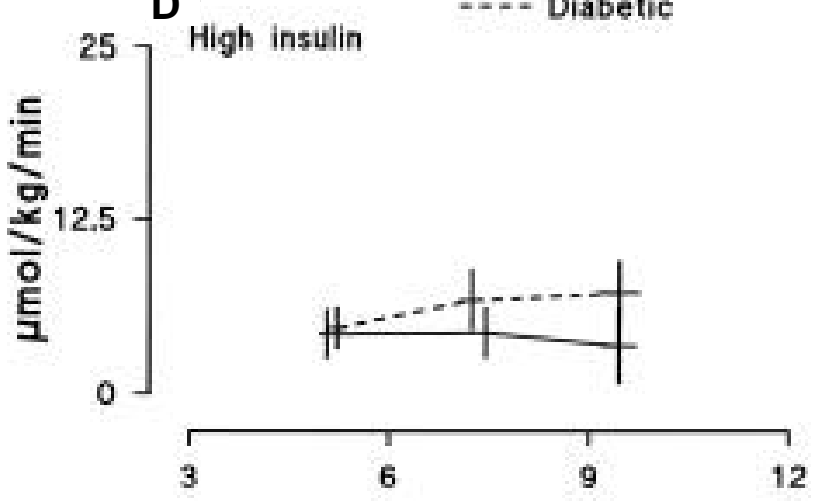

Glucose (mmol/L)

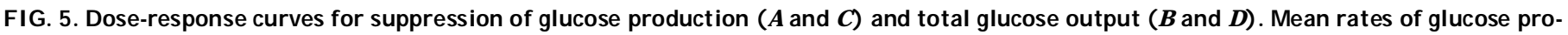

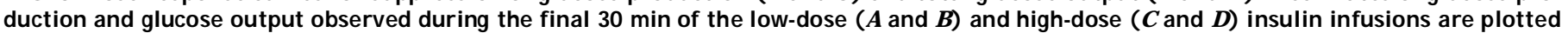
versus the mean plasma glucose concentration observed over the same interval.

experiments of Del Prato et al. suggested that suppression of endogenous glucose production was nonlinear; minimal suppression was observed when glucose concentration was raised from $\sim 90$ to $\sim 145 \mathrm{mg} / \mathrm{dl}$, with marked suppression occurring thereafter. Although those experiments were carefully conducted by an experienced group of investigators, the apparent nonlinearity was probably due to the fact that glucose concentrations were sequentially increased and glucose specific activity was not clamped. The progressive fall in glucose specific activity with each increase in glucose concentration likely resulted in a progressive underestimation of glucose appearance that, in turn, resulted in what appeared to be enhanced suppression of glucose production at higher glucose concentrations $(27,34)$. In contrast, Ader et al. used the constant specific activity method to measure glucose production in dogs (5). In agreement with the present studies, those experiments indicated linear suppression of endogenous glucose production at glucose concentrations within the range commonly observed in nondiabetic humans after food ingestion (i.e., 95-165 mg/dl). However, it is important to emphasize that this conclusion pertains to the presence of basal insulin concentrations. Previous studies have established that permissive amounts of insulin are required for glucose to suppress its own release $(38,40)$. Conversely, an increase in glucose has little or no further effect when glucose production is already markedly suppressed by high insulin concentrations (22).

One of the primary purposes of the present experiments was to determine whether glucose-induced suppression of glucose production is altered by type 2 diabetes. Endogenous glucose production is commonly increased in hyperglycemic individuals with poorly controlled diabetes $(12,41-44)$. This could be due in whole or in part to a failure of glucose to suppress its own release. Alternatively, it could

TABLE 3

Hepatic glucose cycling $\left(\mu \mathrm{mol} \cdot \mathrm{kg}^{-1} \cdot \mathrm{min}^{-1}\right)$

Glucose concentration

\begin{tabular}{|c|c|c|c|c|c|c|}
\hline & \multicolumn{3}{|c|}{ Low-dose insulin (mg/dl) } & \multicolumn{3}{|c|}{ High-dose insulin (mg/dl) } \\
\hline & 95 & 130 & 165 & 95 & 130 & 165 \\
\hline $\begin{array}{l}\text { Diabetic subjects } \\
\text { Nondiabetic subjects }\end{array}$ & $\begin{array}{l}2.61 \pm 1.03 \\
3.94 \pm 0.97\end{array}$ & $\begin{array}{l}3.84 \pm 1.70 \\
6.14 \pm 1.22\end{array}$ & $\begin{array}{l}3.76 \pm 1.25 \\
5.27 \pm 1.72\end{array}$ & $\begin{array}{l}0.70 \pm 1.45 \\
3.31 \pm 1.15\end{array}$ & $\begin{array}{l}3.22 \pm 1.43 \\
3.88 \pm 2.76\end{array}$ & $\begin{array}{l}7.08 \pm 2.39 \\
1.90 \pm 2.65\end{array}$ \\
\hline
\end{tabular}

Data are means $\pm \mathrm{SE}$. 

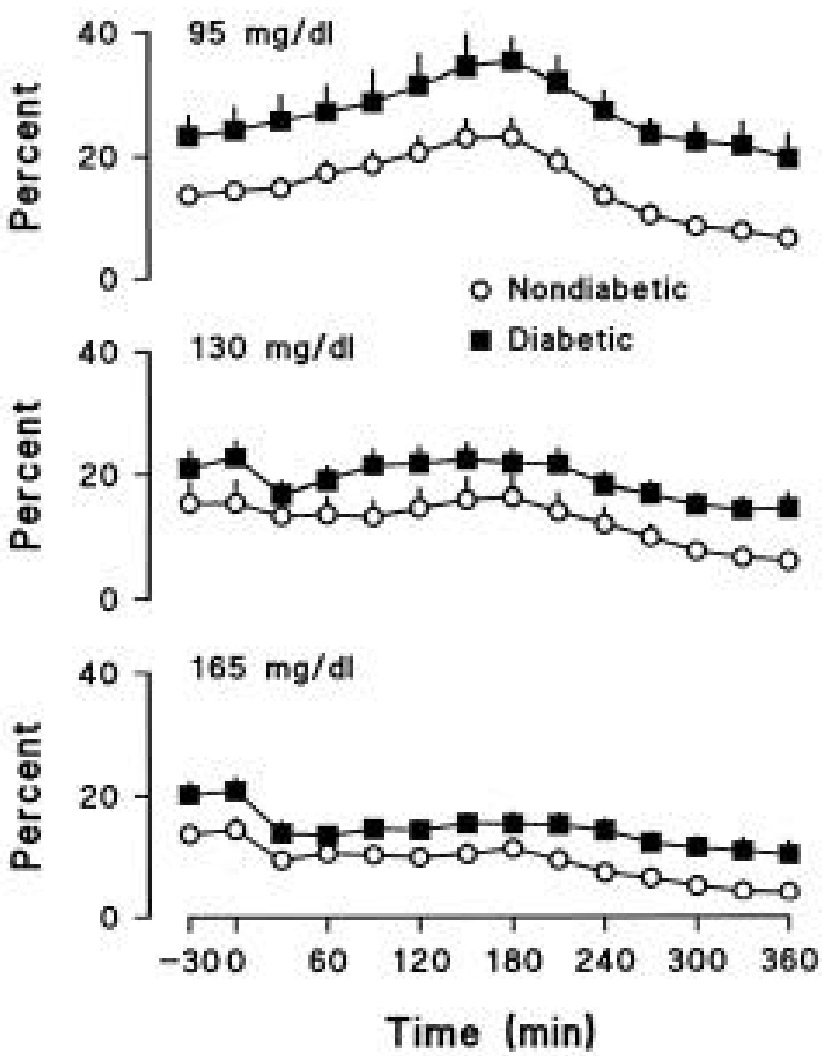

FIG. 6. Percentage of glucose derived from ${ }^{14} \mathrm{CO}_{2}$ observed in the diabetic and nondiabetic subjects when glucose concentration was either clamped at $\sim 95 \mathrm{mg} / \mathrm{dl}$ throughout the entire experiment or acutely increased at time zero to either $\sim 130$ or $\sim 165 \mathrm{mg} / \mathrm{dl}$. The insulin infusion rate was maintained at a constant "basal" rate (referred to as the low-dose insulin infusion) from 0 to $180 \mathrm{~min}$ at which time it was increased to a rate of $0.79 \mathrm{mU} \cdot \mathrm{kg}^{-1} \cdot \mathrm{min}^{-1}$ (referred to as the highdose insulin infusion).

be due to relative insulin deficiency and/or insulin resistance. We have attempted to distinguish between these two possibilities by infusing the diabetic subjects with insulin during the night so that their glucose concentrations would be the same as the nondiabetic subjects at the beginning of each experiment. On the morning of study, insulin secretion was inhibited in both groups by infusing somatostatin, and "basal" insulin concentrations (defined as that required to maintain euglycemia) were determined for each individual. Glucose concentrations were clamped at predetermined levels so that the effects of glucose could be directly compared. When glucose was clamped at $95 \mathrm{mg} / \mathrm{dl}$ during the high-dose insulin infusion (i.e., a traditional euglycemic-hyperinsulinemic clamp), endogenous glucose production was higher and glucose disappearance was lower in the diabetic than in the nondiabetic subjects, indicating that the diabetic subjects were resistant to insulin. Nevertheless, each increment in glucose concentration resulted in a comparable decrement in glucose production in both groups (Fig. 5). As in the nondiabetic subjects, suppression in the presence of basal insulin concentrations over the glucose concentrations tested appeared to be linear. Hyperglycemia also decreased glucose production in the diabetic subjects in the presence of higher insulin concentrations; how ever, the further suppression was limited, since inhibition was already nearly complete.

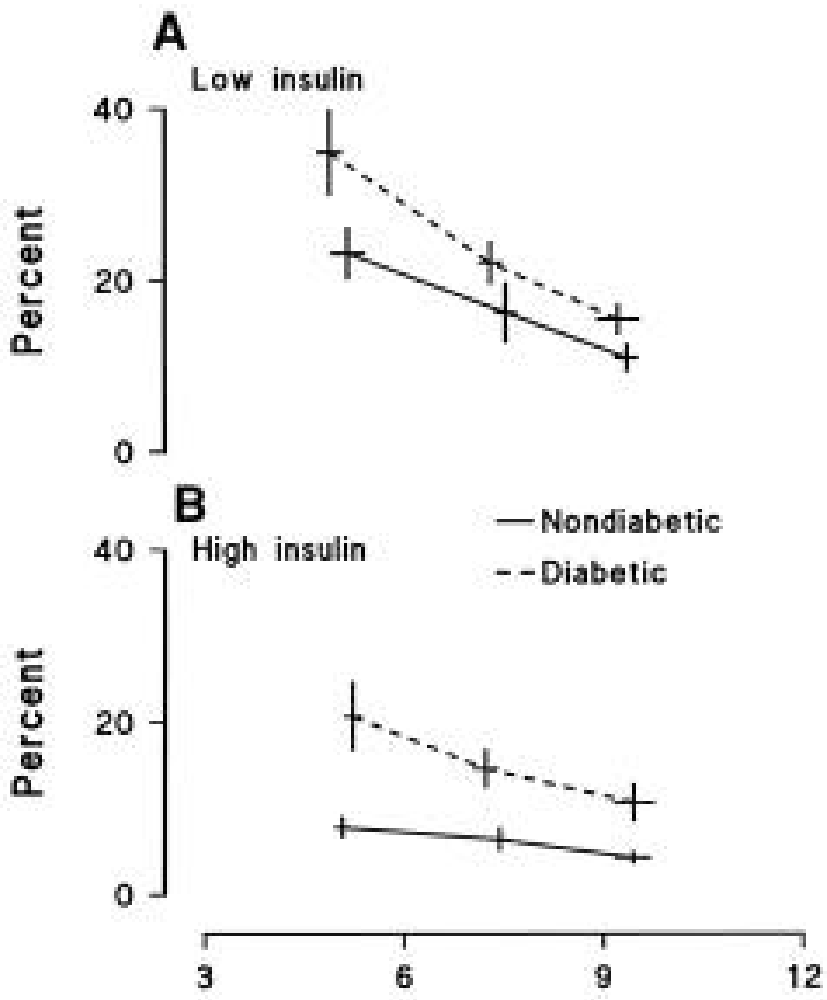

\section{Glucose (mmol/L)}

FIG. 7. Dose-response curves for suppression of the incorporation of ${ }^{14} \mathrm{CO}_{2}$ into glucose. The mean percent of glucose derived from ${ }^{14} \mathrm{CO}_{2}$ observed during the final $30 \mathrm{~min}$ of the low-dose (A) and high-dose (B) insulin infusions is plotted versus the mean glucose concentration observed over the same interval.

Glucose-induced suppression of total glucose output was also equivalent in the diabetic and nondiabetic subjects. Total glucose output was measured with $\left[2-{ }^{3} \mathrm{H}\right]$ glucose, whereas endogenous glucose production was measured with [6$\left.{ }^{3} \mathrm{H}\right] \mathrm{glucose} .\left[2-{ }^{3} \mathrm{H}\right] \mathrm{glucose}$, but not $\left[6-{ }^{3} \mathrm{H}\right] \mathrm{glucose}$, is extensively detritiated when glucose is taken up by the liver, phosphorlyated via glucokinase, dephosphorylated via glucose-6phosphatase, then released back into the systemic circulation $(35,45)$. Thus, turnover measured with $\left[2-{ }^{3} \mathrm{H}\right]$ glucose is higher than that measured with $\left[6-{ }^{3} \mathrm{H}\right]$ glucose, since the former measures the total glucose output whereas the latter measures net glucose production $(29,36,37)$. The difference in rates measured with the two tracers is frequently referred to as "futile" (since energy is consumed) or hepatic glucose cycling. Experiments in both rats and humans have demonstrated that uncontrolled diabetes is associated with increased futile cycling, due, at least in part, to an increase in glucose-6-phosphatase activity $(7,36)$. The present experiments demonstrate that hepatic glucose cycling no longer differs in diabetic and nondiabetic subjects when euglycemia is maintained overnight. This is consistent with the report of Massillon et al. (46) that normalization of glucose in rats with either insulin or the glycosuric agent phlorizin causes rapid normalization of glucose-6-phosphatase gene expression. Perhaps more importantly, an increase in glucose in the presence of basal insulin concentrations comparably decreased total glucose output in both groups, indicating 


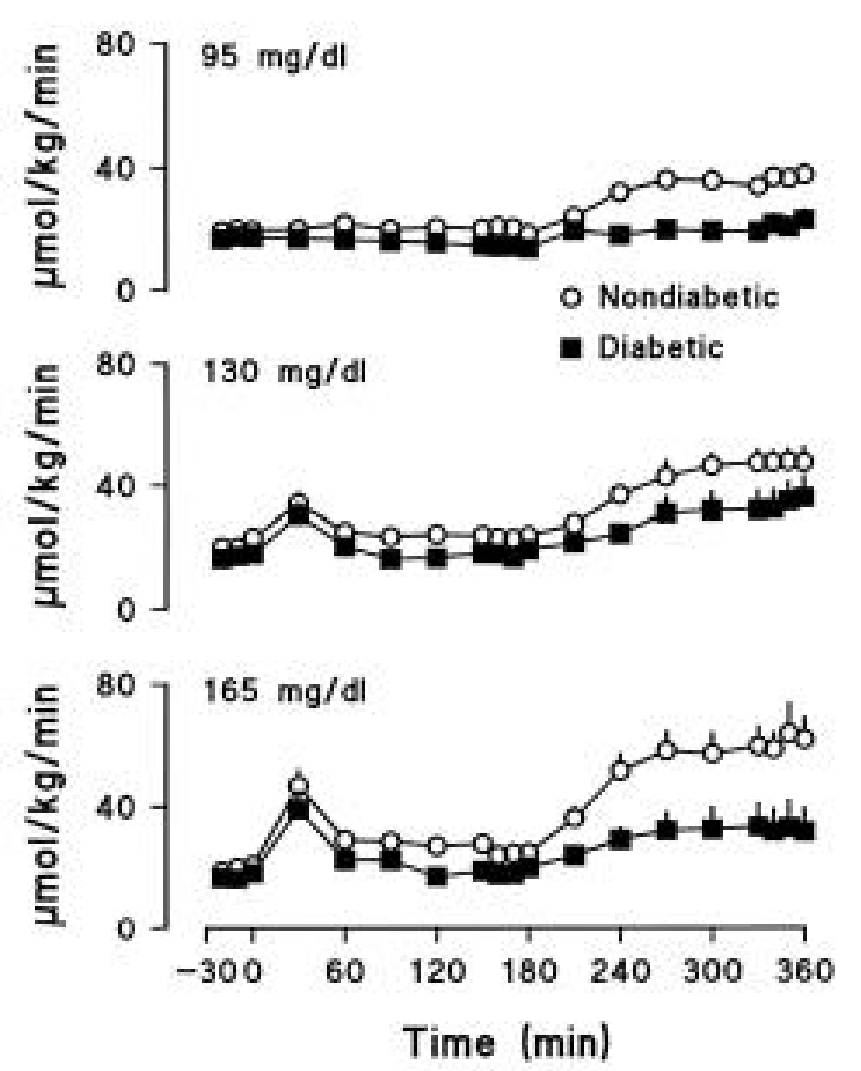

FIG. 8. Rates of glucose disappearance observed in the diabetic and nondiabetic subjects when glucose concentration was either clamped at $\sim 95 \mathrm{mg} / \mathrm{dl}$ throughout the entire experiment or acutely increased at time zero to $\sim 130$ or $\sim 165 \mathrm{mg} / \mathrm{dl}$. The insulin infusion rate was maintained at a constant "basal" rate (referred to as the low-dose insulin infusion) from 0 to $180 \mathrm{~min}$ at which time it was increased to a rate of $0.79 \mathrm{mU} \cdot \mathrm{kg}^{-1} \cdot \mathrm{min}^{-1}$ (referred to as the high-dose insulin infusion).

that hyperglycemic-induced suppression of endogenous glucose production in the diabetic subjects is not offset by an increase in hepatic glucose cycling. Note, however, that the methods used in the present experiments measure only glucose that is released into the systemic circulation (45). Cycling that occurs entirely within either the splanchnic or renal beds is not assessed.

Both in vitro and in vivo studies indicate that poorly controlled diabetes is associated with increased rates of gluconeogenesis $(7,44,47,48)$. Unfortunately, quantitative measurement of gluconeogenesis in humans is difficult $(49,50)$. As discussed elsewhere, we and others have used the rate of incorporation of ${ }^{14} \mathrm{CO}_{2}$ into glucose as a qualitative index of gluconeogenesis $(28,50,51)$. Consistent with previous experiments, insulin-induced suppression of ${ }^{14} \mathrm{CO}_{2}$ incorporation into glucose was impaired in the diabetic subjects ( 52 ). Rates were higher in the diabetic than in the nondiabetic subjects during the high insulin infusion at all three glucose concentrations (Fig. 7). On the other hand, glucose-induced suppression appeared to be intact; this was particularly evident during the basal insulin infusion when suppression was parallel in the diabetic and nondiabetic subjects. Hyperglycemia also suppressed ${ }^{14} \mathrm{CO}_{2}$ incorporation into glucose during the high insulin infusion in the diabetic subjects but not the nondiabetic subjects, where suppression was al ready essentially complete. The overall pattern of suppression of ${ }^{14} \mathrm{CO}_{2}$ incor-

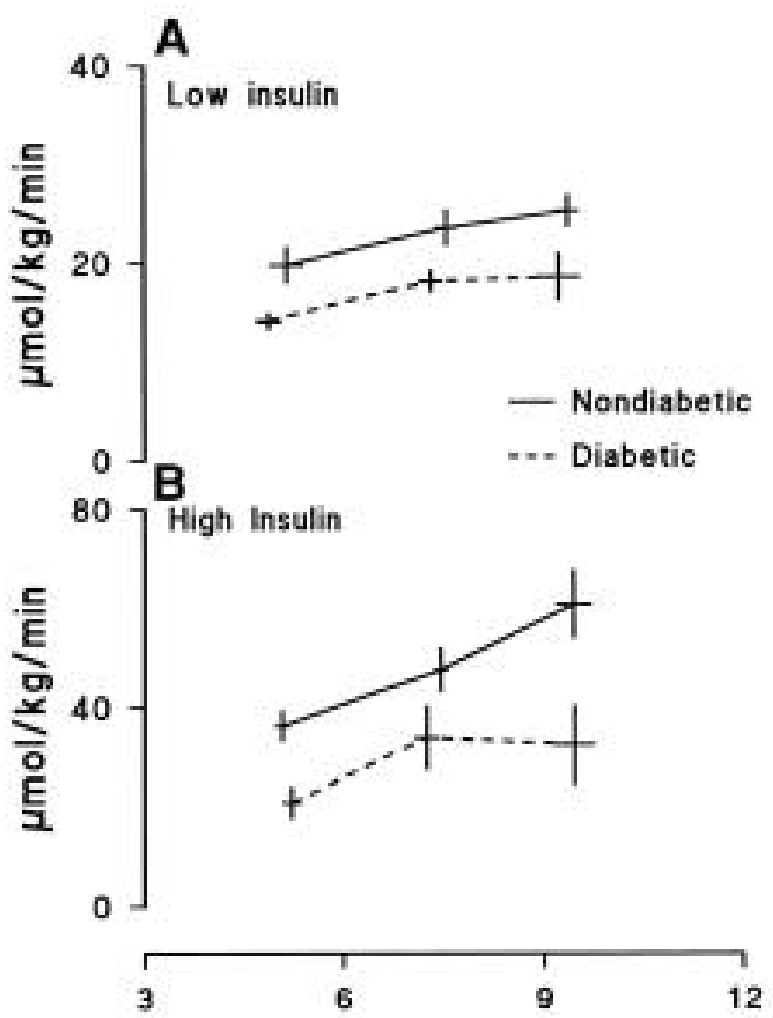

\section{Glucose (mmol/L)}

FIG. 9. Dose-response curves for stimulation of glucose disappearance. The mean rates of glucose disappearance observed during the final 30 min of the low-dose (A) and high-dose (B) insulin infusions are plotted versus the mean glucose concentration observed over the same interval.

poration in the two groups closely resembled that of endogenous glucose production. B ecause endogenous glucose production equals the sum of glycogenolysis and gluconeogenesis, this suggests that hyperglycemia similarly suppressed both processes. Alternatively, hyperglycemia may have merely redirected the G-6-P derived from either glycogenolysis or gluconeogenesis back into glycogen or down the glycolytic pathway (7). Because we have measured only the portion of the newly synthesized $\left[{ }^{14} \mathrm{C}\right]$ glucose that was eventually released into the systemic circulation, and since we have not used a method that quantitatively measures gluconeogenesis, future studies will be required to distinguish between these possibilities.

E ffects of glucose on glucose uptake. The present studies once again confirm that insulin-induced stimulation of glucose uptake is impaired in type 2 diabetes (9-12). They also demonstrate that whereas glucose-induced stimulation of glucose uptake is normal at glucose concentrations below 130 $\mathrm{mg} / \mathrm{dl}$, it is impaired at glucose concentrations above 130 $\mathrm{mg} / \mathrm{dl}$. This pattern was observed at both basal insulin concentrations and insulin concentrations two- to threefold above basal. Numerous investigators (including ourselves) have examined glucose effectiveness in type 2 diabetes, and the results have not always been consistent $(14,15,23,24)$. Many have used the so-called minimal model for this purpose (14-18). This model measures the net effects of glucose on both production and utilization. Most (14-16) but not all (17) 


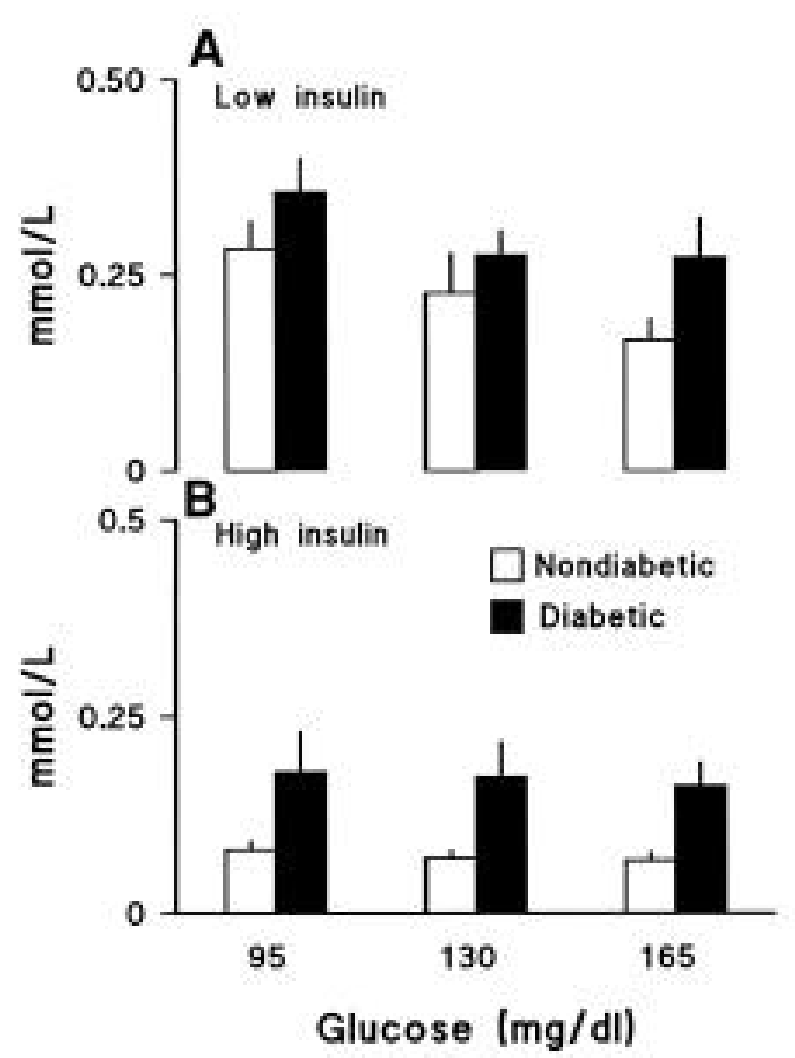

FIG . 10. Mean FFA concentrations during the final $\mathbf{3 0}$ min of the lowdose (A) and high-dose (B) insulin infusions when glucose concentrations were either maintained at $\sim 95 \mathrm{mg} / \mathrm{dl}$ throughout the experiment or acutely increased at time zero to either $\sim 135$ or $\sim 165 \mathrm{mg} / \mathrm{dl}$.

of these studies have found that $S_{G}$ is decreased in individuals with type 2 diabetes. When interpreted in light of the demonstration in the present study that glucose-induced suppression of glucose release is normal in type 2, these studies are consistent with a decrease in glucose-induced stimulation of glucose disposal. This conclusion is supported by several additional studies. Both we (23), using a prandial glucose infusion, and Avogaro et al. (25), using the so-called hot minimal model, have previously shown that glucose-induced stimulation of glucose uptake is impaired in the presence of basal insulin concentrations in type 2 diabetes. In addition, Del Prato et al. (24), using the glucose clamp technique, and Mandarino et al. (53), using the leg balance method, have also reached the same conclusion.

In contrast, Baron et al. (54) and Capaldo et al. (55) have reported that glucose-mediated uptake is either normal or increased in type 2 diabetes. However, both of these investigators examined uptake in the presence of zero insulin concentrations (frequently referred to as non-insulin-mediated glucose uptake). While of considerable theoretical interest, the physiological significance of these findings is uncertain because insulin concentrations are rarely, if ever, zero in people with type 2 diabetes. Of perhaps more concern are our own previous results. We failed to detect an abnormality in glucose-induced stimulation of uptake in type 2 diabetes in another series of experiments in which glucose effectiveness was assessed in the presence of an insulin concentration normally observed in nondiabetic subjects after food ingestion (22). We were puzzled by those results when we subse- quently found, as noted above, that glucose stimulation of disposal was impaired in the presence of basal insulin concentrations (23). We speculated that the discrepant results were due to the differences in insulin concentrations between the two experiments. The present experiments indicate that this was not the case but rather suggest that the differences were due to differences in glucose concentrations. In our earlier experiments, we calculated glucose effectiveness by subtracting glucose disposal rates observed when glucose concentrations were varied so as to mimic postprandial levels from those observed when glucose was clamped at euglycemic levels (22). Because we were mimicking a nondiabetic profile, glucose concentrations were only briefly above 130 $\mathrm{mg} / \mathrm{dl}$. In contrast, since glucose concentrations were permitted to rise unencumbered in our experiment in which glucose effectiveness was assessed in the presence of basal insulin levels, concentrations in excess of $220 \mathrm{mg} / \mathrm{dl}$ were reached in the diabetic subjects (23). The demonstration in the present experiments that the ability of glucose to stimulate its own disposal is impaired in diabetic subjects at glucose concentrations above, but not below, $130 \mathrm{mg} / \mathrm{dl}$ explains why an abnormality in glucose effectiveness was detected in the latter but not the former experiments. It also explains why experiments using the minimal model have generally found $\mathrm{S}_{\mathrm{G}}$ to be decreased, since the diabetic subjects were invariably hyperglycemic at the time of study and since glucose concentrations rose to extremely high levels after intravenous glucose injection (14-16,18,25).

The observation that the glucose dose-response curve for stimulation of glucose uptake flattens at a lower concentration in diabetic than in nondiabetic subjects implies saturation of a rate-limiting step that is regulated by glucose. Although this early flattening was not commented on in the experiments of Del Prato et al. (24), this likely reflects the fact that the first step in glucose concentration (to $\sim 155 \mathrm{mg} / \mathrm{dl}$ ) was above the apparent threshold ( $130 \mathrm{mg} / \mathrm{dl})$ noted in the present studies. In addition, the increment in uptake was calculated by subtracting baseline rates of disappearance determined before initiation of the somatostatin and basal hormone infusions from rates of disappearance determined several hours later. Finally, progressive increases in urinary glucose excretion presumably contributed to the apparent increments in glucose uptake that were observed in the diabetic subjects when glucose was sequentially increased to $\sim 210$ and $\sim 300 \mathrm{mg} / \mathrm{dl}$, thereby obscuring the effects of glucose on tissue glucose utilization. While these factors confound interpretation of the shape of the glucose dose-response curves for disappearance, they do not detract from the fact that the differences between the diabetic and nondiabetic subjects in the experiments of Del Prato et al. (24) were substantial, strongly implying that the ability of glucose to stimulate glucose uptake in the presence of basal insulin concentrations was impaired in type 2 diabetes.

Glucose transport/phosphorylation is a likely candidate for the decrease in uptake, since previous studies have shown that it is rate limiting at low levels of flux $(6,56,57)$. In this regard, it is important to note that the insulin concentrations present during the so-called high-dose insulin study fall on the lower portion of the insulin dose-response curve for stimulation of glucose uptake $(8,9,58)$. Early saturation of transport could result from a decrease in the number or function of membrane-bound glucose transporters. Alternatively, 
a more distal step such as phosphorylation or glycogen synthesis could become rate limiting at higher glucose concentrations. Transport, phosphorylation, and glycogen synthesis are all modulated by both glucose and insulin concentrations $(6,59,60)$. Insulin-induced regulation of all three processes has been reported to be abnormal in type 2 diabetes $(56,57,61-64)$. A defect in glucose-induced regulation of any or all of these processes could explain the present findings. Such a defect could be due to an intrinsic abnormality in a common intracellular signaling pathway or could be secondary to the metabolic milieu associated with type 2 diabetes (e.g., elevated FFAs, such as those observed in the present experiments). Whatever the mechanism, it is likely not a simple matter of a decrease in the absolute number/activity of transporters; an increase in glucose concentration in the diabetic subjects from 95 to $130 \mathrm{mg} / \mathrm{dl}$ further stimulated uptake during the high-dose insulin infusion but did not do so when glucose was increased from 130 to $165 \mathrm{mg} / \mathrm{dl}$ during the lowdose insulin infusion despite the fact that the absolute rate of disposal was greater in the former than in the latter instance. Alternatively, the defect may reside in the liver rather than in muscle. If so, then this would imply abnormal regulation of hepatic enzyme activity, since transport does not limit glucose uptake in this tissue. Additional studies will be required to distinguish between these possibilities.

Limitations. As with all experiments, the present studies have certain limitations. We have only examined glucose effectiveness between glucose concentrations of 95 and 165 $\mathrm{mg} / \mathrm{dl}$. We chose this range for both theoretical and practical reasons. First, it encompasses the concentrations normally observed in nondiabetic humans before and after food ingestion (1-3). Second, it is below the renal threshold of most individuals, thereby minimizing the uncertainty introduced by the need to correct glucose disappearance for urinary glucose losses. Third, in our experience, glucose concentrations above $165 \mathrm{mg} / \mathrm{dl}$ frequently cause a breakthrough in insulin secretion despite the presence of somatostatin, and glucose concentrations below $95 \mathrm{mg} / \mathrm{dl}$ are frequently accompanied by secretion of counterregulatory hormones. Both occurrences confound assessment of insulin action and glucose effectiveness. Therefore, the present experiments do not permit comment on glucose effectiveness above $165 \mathrm{mg} / \mathrm{dl}$ or below $95 \mathrm{mg} / \mathrm{dl}$.

Similarly, we only examined two insulin concentrations. We chose to study "basal" insulin concentration because this potentially provides insight into the effects of glucose after an overnight fast and because this is the insulin concentration at which the widely used minimal model estimates glucose effectiveness (13). We chose the high-dose insulin infusion because it results in insulin concentrations that fall on the lower portion of the insulin dose-response curve for the stimulation of glucose uptake $(8,9,58)$ and that approximate insulin concentrations frequently observed after eating a mixed meal (1-3). As previously discussed in detail $(22,23)$, we chose to individually determine appropriate "basal" insulin concentration (defined as that required to maintain euglycemia) for each subject on each study day. Because of the presence of insulin resistance, this resulted in slightly higher insulin concentrations in diabetic than in nondiabetic subjects. Alternatively, we could have used the same basal insulin infusion rate in both groups; however, this approach would likely have resulted in glucose concentrations that were ris- ing in the diabetic subjects at the start of the experiments. In this instance, we potentially would incorrectly conclude that the rising glucose concentration and its associated inappropriately high rates of glucose production and inappropriately low rates of glucose uptake were due to defects in glucose effectiveness when in fact they were due to relative insulin deficiency. We adopted the alternative approach (i.e., we used the same insulin infusion rate in both groups) during the higher dose insulin study because we were primarily interested in glucose disposal and therefore wanted to ensure that peripheral insulin concentrations were the same in both groups. While both approaches have their limitations, the fact that they both yielded concordant results during the low and high insulin infusions is obviously reassuring.

Insulin was infused during the night in the diabetic subjects so that glucose concentrations would be the same in both groups at the beginning of the experiments. We have previously demonstrated that while insulin resistance persists after overnight insulin infusion (52), insulin administration and/or the associated improvement in glycemic control improves hepatic but not extrahepatic insulin action (65). In contrast, we have found in preliminary experiments that overnight insulin infusion does not alter glucose effectiveness (R.B., unpublished observations). Thus, while the present experimental design may have underestimated the severity of hepatic insulin resistance, it is unlikely to have had an impact on the assessment of glucose effectiveness. Because the studies were conducted in humans, insulin was infused into the peripheral rather than into the portal venous system. While it is possible that different conclusions would have been reached if insulin had been infused into the portal circulation, we doubt it, since recent studies have shown similar hepatic responses regardless of the route of infusion (66-68). C-peptide concentrations increased from 0.05 to $0.09 \mathrm{nmol} / \mathrm{l}$ in the nondiabetic subjects when glucose was raised to $165 \mathrm{mg} / \mathrm{dl}$. Assuming that this was accompanied by an increase in portal insulin concentrations, this would have been a conservative error, since, if anything, it would have overestimated glucose-induced suppression of glucose production in the nondiabetic subjects. We measured $\left[6-{ }^{3} \mathrm{H}\right] \mathrm{glu}$ cose and $\left[2-{ }^{3} \mathrm{H}\right]$ glucose specific activities in the peripheral circulation rather than in the hepatic bed. Because we do not know specific activity within the hepatic bed, we also do not know total rates of hepatic glucose cycling (45). Similarly, we do not know whether the relative contribution of the kidney and liver to systemic glucose production differed in the diabetic and nondiabetic subjects. We merely know that net response of the tissues to an increase in glucose was equal in both groups.

We used the rate of incorporation of ${ }^{14} \mathrm{CO}_{2}$ into glucose as an index of gluconeogenesis. The advantages and disadvantages of this technique have been discussed in detail elsewhere $(28,50,51)$. Because labeling occurs as pyruvate is converted to oxaloacetate by pyruvate carboxylase, this method suffers from the same limitations as does the use of alanine or lactate for the same purpose (49-51). How ever, dilution within the oxaloacetate pool appears to remain relatively constant under a wide range of conditions $(50,69,70)$. Therefore, it is likely that the similar pattern of change in the incorporation of ${ }^{14} \mathrm{CO}_{2}$ into glucose in the diabetic and nondiabetic subjects reflects a similar degree of suppression of the contribution of gluconeogenesis to systematically released glu- 
cose. We did not correct glucose disappearance for urinary glucose loss; although we measured total urinary glucose excretion during the clamps, we do not know whether the rate of excretion was the same throughout the $6 \mathrm{~h}$ of study. Nevertheless, this represents a conservative error, since urinary glucose excretion was trivial in the nondiabetic subjects at all glucose concentrations but averaged up to $1-2 \mu \mathrm{mol} \cdot \mathrm{kg}^{-1}$. $\mathrm{min}^{-1}$ in some of the diabetic subjects during the $165 \mathrm{mg} / \mathrm{dl}$ clamp. Therefore, subtraction of urinary losses from tracerdetermined rates of glucose disappearance would further flatten the dose-response curve for glucose uptake in the diabetic subjects. The BMI of the diabetic subjects averaged $26 \mathrm{~kg} / \mathrm{m}^{2}$ with a range of $18-33 \mathrm{~kg} / \mathrm{m}^{2}$. Additional studies will be required to determine whether the conclusions of the present study apply to more obese type 2 diabetic subjects. Of note, the BMI of the diabetic subjects was slightly but not significantly greater than that of the nondiabetic subjects. However, percent visceral fat was virtually identical in both groups (Table 1), implying that the impaired hepatic response to insulin but normal responses to glucose in the diabetic relative to the nondiabetic subjects cannot be attributed to differences in visceral adiposity.

Summary. In conclusion, the present experiments once again show that people with type 2 diabetes have both hepatic and extrahepatic insulin resistance. However, their response to glucose may or may not be abnormal depending on the tissue involved. In the presence of basal insulin concentrations, an increase in glucose over the range of 95-165 $\mathrm{mg} / \mathrm{dl}$ causes a progressive and comparable decrease in endogenous glucose production and total glucose output in both diabetic and nondiabetic subjects, implying a normal hepatic (and perhaps renal) response to glucose. In contrast, the ability of glucose to stimulate its own uptake is impaired. This defect is evident at glucose concentrations above 130 $\mathrm{mg} / \mathrm{dl}$ and is observed in the presence of low and high insulin concentrations. Thus, these studies provide experimental support for the assumption that glucose-induced suppression of its own release is linear and does not differ in diabetic and nondiabetic humans. They also imply that therapies that enhance glucose-induced, as well as insulin-induced, stimulation of glucose uptake are likely to improve glycemic tolerance in people with type 2 diabetes.

\section{ACKNOWLE DGMENTS}

This study was supported by the U.S. Public Health Service (DK-29953, RR-00585), the Mayo General Clinical Research Center, the Ministero Universita Ricerca Scientifica Tecnica (Murst), Italy, and the Mayo Foundation. M.F.N. was supported by research grants provided by the Danish Research Council, Aarhus University Hospital, and the University of Aarhus, Aarhus, Denmark.

We thank C. Etter, T. Madson, and D. Nash for technical assistance; $\mathrm{A}$. Wagner for assistance in preparation of the manuscript; and the staff of the Mayo General Clinical Research Center for assistance in performing the studies.

\section{RE FERE NCES}

1. Firth RG, Bell PM, Marsh HM, Hansen I, Rizza RA: Postprandial hyperglycemia in patients with non-insulin-dependent diabetes mellitus. J Clin Invest 77:1525-1532, 1986

2. Mitrakou A, Kelley D, Veneman T, Jenssen T, Pangburn T, Reilly J, Gerich J Contribution of abnormal muscle and liver glucose metabolism to postprandial hyperglycemia in NIDDM. Di abetes 39:1381-1390, 1990
3. Ferrannini E, Simonson DC, Katz LD, Reichard G J r, Bevilacqua S, Barrett EJ, Olsson M, DeF ronzo RA: The disposal of an oral glucose load in patients with non-insulin-dependent diabetes. Metabolism 37:79-85, 1988

4. Defronzo RA, Ferrannini E, Hendler R, Felig P, Wahren J : Regulation of splanchnic and peripheral glucose uptake by insulin and hyperglycemia in man. Di abetes 32:35-45, 1983

5. Ader M, Ni T, Bergman RN: Glucose effectiveness assessed under dynamic and steady-state conditions. J Clin Invest 99:1187-1199, 1997

6. Yki-j arvinen $\mathrm{H}$, Young AA, Lamkin C, Foley J E : Kinetics of glucose disposal in whole body and across the forearm in man.J Clin Invest 79:1713-1719, 1987

7. Rossetti L, Giaccari A, Barzilai N, Howard K, Sebel G, Hu M: Mechanism by which hyperglycemia inhibits hepatic glucose production in conscious rats. J Clin Invest 92:1126-1134, 1993

8. Rizza RA, Mandarino LJ , Gerich J E : Dose-response characteristics for effects of insulin on production and utilization of glucose in man. Am J Physiol 240:E 630-E 639, 1981

9. Kolterman OG, Gray RS, Griffin J, Burstein P, Insel J, Scarlett ] A, Olefsky J M: Receptor and postreceptor defects contribute to the insulin resistance in non-insulin-dependent diabetes mellitus. J Clin Invest 68:957-969, 1981

10. Firth R, Bell P, Rizza R: Insulin action in non-insulin-dependent diabetes mellitus: the relationship between hepatic and extrahepatic insulin resistance and obesity. Metabolism 36:1091-1095, 1987

11. Bogardus C, Lillioja S, Howard BV, Reaven G, Mott D: Relationships between insulin secretion, insulin action, and fasting plasma glucose concentration in nondiabetic and non-insulin-dependent diabetic subjects. J Clin Invest 74:1238-1246, 1984

12. Firth RG, Bell PM, Rizza RA: Effects of tolazamide and exogenous insulin on insulin action in patients with non-insulin-dependent diabetes mellitus. N Engl J Med 314:1280-1286, 1986

13. Bergman RN, Ider YZ, Bowden CR, Cobelli C: Quantitative estimation of insulin sensitivity. Am J Physi ol 236:E667-E677, 1979

14. Taniguchi A, Nakai $Y$, Fukushima M, Kawamura $H$, Imura $H$, Naga I, Tokuyama K: Pathogenic factors responsible for glucose intolerance in patients with NIDDM. Di abetes 41:1540-1546, 1992

15. Wajchenberg BL, Santomauro ATMG, Porrelli RN: Effect of a sulfonylurea (gliclazide) treatment on insulin sensitivity and glucose-mediated glucose disposal in patients with non-insulin-dependent diabetes mellitus (NIDDM). Di abetes Res Clin Pract 20:147-154, 1993

16. Welch S, Gebhart SSP, Bergman RN, Phillips LS: Minimal model analysis of intravenous glucose tolerance test-derived insulin sensitivity in diabetic subjects. J Clin Endocrinol Metab 71:1508-1518, 1990

17. Davis SN, Monti L, Piatti PM, Moller N, Ng L, Coppack S, Brown MD, Orskov $H$, Alberti KG: Estimates of insulin action in normal, obese, and NIDDM man: comparison of insulin and glucose infusion test, CIGMA, minimal model, and glucose clamp techniques. Di abetes Res 23:1-18, 1993

18. Kruszynska YT, Harry DS, Bergman RN, McIntyre N : Insulin sensitivity, insulin secretion, and glucose effectiveness in diabetic and nondiabetic cirrhotic patients. Di abetologi a 36:121-128, 1993

19. Quon MJ , Cochran C, Taylor SI, Eastman RC: Non-insulin-mediated glucose disappearance in subjects with IDDM. Di abetes 43:890-896, 1994

20. Caumo A, Vicini P, Cobelli C: Is minimal model too minimal? Diabetologia 39:997-1000, 1996

21. Finegood DT, Tzur D: Reduced glucose effectiveness associated with reduced insulin release: an artifact of the minimal-model method. Am J Physiol 271:E 485-E 495, 1996

22. Alzaid AA, Dinneen SF, Turk DJ , Caumo A, Cobelli C, Rizza RA: Assessment of insulin action and glucose effectiveness in diabetic and nondiabetic humans. J Clin Invest 94:2341-2348, 1994

23. Basu A, Caumo A, Bettini F, Gelisio A, Alzaid A, Cobelli C: Impaired basal glucose effectiveness in NIDDM: contribution of defects in glucose disappearance and production, measured using an optimized minimal model independent protocol. Diabetes 46:421-432, 1997

24. Del Prato S, Matsuda M, Simonson DC, Groop LC, Sheehan P, Leonetti F, Bonadonna RC, DeF ronzo RA: Studies on the mass action effect of glucose in NIDDM and IDDM: evidence for glucose resistance. Diabetologia 40:687-697, 1997

25. Avogaro A, Vicini P, Valerio A, Caumo A, Cobelli C: The hot but not the cold minimal model allows precise assessment of insulin sensitivity in NIDDM subjects. Am J Physi ol 270:E532-E540, 1996

26. White NH, Skor D, Santiago JV: Practical closed-loop insulin delivery: a system for the maintenance of overnight euglycemia and the calculation of basal insulin requirements in insulin-dependent diabetics. Ann Intern Med 97:210-213, 1982

27. Finegood DT, Bergman RN, Vranic M: Modeling error and apparent isotope discrimination confound estimation of endogenous glucose production during euglycemic glucose clamps. Diabetes 37:1025-1034, 1988

28. MCMahon M, Marsh HM, Rizza RA: Effects of basal insulin supplementation 
on disposition of mixed meal in obese patients with NIDDM. Diabetes 38:291-303, 1989

29. Bell PM, Firth RG, Rizza RA: Assessment of insulin action in insulin-dependent diabetes mellitus using $\left[6^{14} \mathrm{C}\right] g l u c o s e,\left[3^{3} \mathrm{H}\right]$ glucose, and $\left[2^{3} \mathrm{H}\right]$ glucose. J Clin Invest 78:1479-1486, 1986

30. J ensen MD, Kanaley JA, Reed J E, Sheedy PF: Measurement of abdominal and visceral fat with computed tomography and dual-energy X-ray absorptiometry. AmJ Clin Nutr 61:274-278, 1995

31. Bradley DC, Steil GM, Bergman RN: Quantitation of measurement error with optimal segments: basis for adaptive time course smoothing. Am J Physiol 264:E 902-E 911, 1993

32. Steele R, Wall J S, De Bodo RC, Altszuler N, Kiang SP, Bjerknes C: Measurement of size and turnover rate of body glucose pool by the isotope dilution method. Am J Physi ol 187:15-24, 1956

33. Caumo A, Homan M, Katz H, Cobelli C, Rizza R: Glucose turnover in presence of changing glucose concentrations: error analysis for glucose disappearance. AmJ Physi ol 269:E 557-E 567, 1995

34. Butler PC, Caumo A, Zerman A, O'Brien PC, Cobelli C, Rizza RA: Methods for assessment of the rate of onset and offset of insulin action during nonsteady state in humans. Am J Physi ol 264:E548-E 569, 1993

35. Katz J , Rognstad R: Futile cycles in the metabolism of glucose. Curr Top Cell Regul 10:237-289, 1976

36. Efendic $S$, Wajngot $A$, Vranic $M$ : Increased activity of the glucose cycle in the liver: early characteristic of type 2 diabetes. Proc Natl Acad Sci U S A 82:2965-2969, 1985

37. Butler RC, Rizza RA: Contribution to postprandial hyperglycemia and effect on initial splanchnic glucose clearance of hepatic glucose cycling in glucoseintolerant or NIDDM patients. Di abetes 40:73-81, 1991

38. Sacca L, Hendler R, Sherw in RS: Hyperglycemia inhibits glucose production in man independent of changes in glucoregulatory hormones. J Clin Endocrinol Metab 47:1160-1161, 1978

39. McMahon MM, Schwenk WF, Haymond MW, Rizza RA: Underestimation of glucose turnover measured with $\left[6-{ }^{3} \mathrm{H}\right]-$ and $\left[6,6-{ }^{2} \mathrm{H}_{2}\right]$ - but not $\left[6-{ }^{14} \mathrm{C}\right]$ glucose during hyperinsulinemia in humans. Di abetes 38:97-107, 1989

40. Davidson MB: Autoregulation by glucose of hepatic balance: permissive effect of insulin. Metabolism 30:279-284, 1981

41. Mitrakou A, Kelley D, Mokan M, Veneman T, Pangburn T, Reilly J, Gerich J : Role of reduced suppression of glucose production and diminished early insulin release in impaired glucose tolerance. N Engl J Med 326:22-29, 1992

42. Bonora E, Bonadonna RC, Del Prato S, Gulli G, Solini A, Matsuda M, DeF ronzo RA: In vivo glucose metabolism in obese and type II diabetic subjects with or without hypertension. Di abetes 42:764-772, 1993

43. Henry RR, Gumbiner B, Ditzler T, Wallace P, Lyon R, Glauber HS: Intensive conventional insulin therapy for type II diabetes. Di abetes Care 16:21-31, 1993

44. Magnusson I, Rothman DL, Katz LD, Shulman RG, Shulman GI: Increased rate of gluconeogenesis in type II diabetes mellitus.J Clin Invest 90:1323-1327, 1992

45. Wajngot A, Chandramouli V, Schumann WC, Kumaran K, Efendic S, Landau BR: Testing of the assumptions made in estimating the extent of futile cycling. AmJ Physi ol 256:E668-E675, 1989

46. Massillon D, Barzilai N, Chen W, Hu M, Rossetti L: Glucose regulates in vivo glucose-6-phosphatase gene expression in the liver of diabetic rats. J Biol Chem 271:9871-9874, 1996

47. Consoli A, Nurjhan N, Capani F, Gerich J : Predominant role of gluconeogenesis in increased hepatic glucose production in NIDDM. Di abetes 38:550-557, 1989

48. Yki-- ärvinen $\mathrm{H}$, Helve E, Sane T, Nurjhan $\mathrm{N}$, Taskinen M: Insulin inhibition of overnight glucose production and gluconeogenesis from lactate in NIDDM. Am J Physi ol 256:E 732-E 739, 1989

49. Brosnan JT: Pathways of carbon flux in gluconeogeneis. Fed Proc 41:91-94, 1982

50. Katz J : Determination of gluconeogenesis in vivo with ${ }^{14} \mathrm{C}$-labeled substrates. AmJ Physiol 17:391-399, 1985
51. Esenmo E, Chandramouli V, Schumann WC, Kumaran K, Wahren J, Landau BR: U se of ${ }^{14} \mathrm{CO}_{2}$ in estimating rates of hepatic gluconeogenesis. AmJ Phys iol 263:E 36-E 41, 1992

52. Turk D, Alzaid A, Dinneen S, Nair KS, Rizza R: The effects of non-insulin-dependent diabetes mellitus on the kinetics of onset of insulin action in hepatic and extrahepatic tissues. J Clin Invest 95:755-762, 1995

53. Mandarino LJ , Consoli A, J ain A, Kelley DE: Interaction of carbohydrate and fat fuels in human skeletal muscle: impact of obesity and NIDDM. Am J Physiol 270:E 463-E470, 1996

54. Baron AD, Kolterman OG, B ell J, Mandarino LJ, Olefsky J M: Rates of noninsulin-mediated glucose uptake are elevated in type II diabetic subjects.J Clin Invest 76:1782-1788, 1985

55. Capaldo B, Santoro D, Riccardi G, Perrotti N, Sacca L: Direct evidence for a stimulatory effect of hyperglycemia per se on peripheral glucose disposal in type II diabetes. J Clin Invest 77:1285-1290, 1986

56. Bonadonna RC, Del Prato S, Bonora E, Saccomani MP, Guilli G, Natali A, Frascerra S, Pecori N, Ferrannini E, Bier D, Cobelli C, DeFronzo RA: Roles of glucose transport and glucose phosphorylation in muscle insulin resistance of NIDDM. Di abetes 45:915-925, 1996

57. Rothman DL, Shulman RG, Shulman GI: ${ }^{31} \mathrm{P}$ nuclear magnetic resonance measurements of muscle glucose-6-phosphate. J Clin Invest 89:1069-1075, 1992

58. Katz H, Butler P, Homan M, Zerman A, Caumo A, Cobelli C, Rizza R: Hepatic and extrahepatic insulin action in humans: measurement in the absence of non-steady-state error. AmJ Physiol 264:E 561-E566, 1993

59. Ferrannini E, Locatelli L, J equier E, Felber JP: Differential effects of insulin and hyperglycemia on intracellular glucose disposition in humans. Metaboli sm 38:459-465, 1989

60. Ronan R, Velho G, Carlier PG, J ouvensal L, Bloch G: In vivo NMR evidence for moderate glucose accumulation in human skeletal muscle during hyperglycemia. Am J Physi ol 271:E 434-E 438, 1996

61. Shulman GI, Rothman DL, Jue T, Stein P, DeFronzo RA, Shulman RG: Quantitation of muscle glycogen synthesis in normal subjects and subjects with noninsulin-dependent diabetes by ${ }^{13} \mathrm{C}$ nuclear magnetic resonance spectroscopy. N Engl J Med 322:223-228, 1990

62. Henry RR, Gumbiner B, Flynn T, Thorburn AW: Metabolic effects of hyperglycemia and hyperinsulinemia on fat of intracellular glucose in NIDDM. Di abetes 39:149-156, 1990

63. Vaag A, Damsbo P, Hother-Nielsen O, Beck-Nielsen H: Hyperglycaemia compensates for the defects in insulin-mediated glucose metabolism and in the activation of glycogen synthase in the skeletal muscle of patients with type 2 (noninsulin-dependent) diabetes mellitus. Diabetol ogia 35:80-88, 1992

64. Kelley DE, Mandarino LJ : Hyperglycemia normalizes insulin-stimulated skeletal muscle glucose oxidation and storage in non-insulin-dependent diabetes mellitus. J Clin Invest 86:1999-2007, 1990

65. Wise SD, Nielsen MF, Cryer PE, Rizza RA: Overnight normalization of glucose concentrations improves hepatic but not extrahepatic insulin action in subjects with type 2 diabetes mellitus.J Clin Endocrinol Metab 83:2461-2469, 1998

66. Katz H, Homan M, Velosa J, Robertson P, Rizza R: Effects of pancreas transplantation on postprandial glucose metabolism. N Engl J Med 325:1278-1283, 1991

67. Bradley DC, Poulin RA, Bergman RN: Dynamics of hepatic and peripheral insulin effects suggest common rate-limiting step in vivo. Diabetes 42:296-306, 1993

68. Giacca A, Fisher SJ , Shi ZQ, Gupta R, Lickley HLA, Vranic M: Importance of peripheral insulin levels for insulin-induced suppression of glucose production in depancreatized dogs. J Clin Invest 90:1769-1777, 1992

69. Neese RA, Schwarz J , Faix D, Turner S, Letscher A, Vu D, Hellerstein MK: Gluconeogenesis and intrahepatic triose phosphate flux in response to fasting or substrate loads. J Bi ol Chem 270:14452-14463, 1995

70. Katz J Wals P, Lee WP: I sotopomer studies of gluconeogenesis and the Krebs cycle with ${ }^{13} \mathrm{C}$-labeled lactate. J Bi ol Chem 268:25509-25521, 1993 
Author Queries (please see Q in margin and underlined text)

Q1: Mayo OK here and in acknowledgments? Also, would you like the Mayo Clinic referred to this way in affiliations?

What is the correct spelling of Ggebhart or Gebhart in ref. 16?

Please update ref. 65 with volume, pages and year if already published>

In ref 70 , is Paul Lee the last name?> 